Federal Reserve Bank of New York

Staff Reports

\title{
Tuition, Jobs, or Housing: What's Keeping Millennials at Home?
}

\author{
Zachary Bleemer \\ Meta Brown \\ Donghoon Lee \\ Wilbert van der Klaauw
}

Staff Report No. 700

November 2014

Revised July 2017

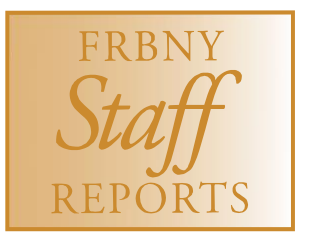

This paper presents preliminary findings and is being distributed to economists and other interested readers solely to stimulate discussion and elicit comments. The views expressed in this paper are those of the authors and do not necessarily reflect the position of the Federal Reserve Bank of New York or the Federal Reserve System. Any errors or omissions are the responsibility of the authors. 
Tuition, Jobs, or Housing: What's Keeping Millennials at Home?

Zachary Bleemer, Meta Brown, Donghoon Lee, and Wilbert van der Klaauw

Federal Reserve Bank of New York Staff Reports, no. 700

November 2014; revised July 2017

JEL classification: D14, E24, R21

\begin{abstract}
This paper documents marked changes in young Americans' residence choices over the past fifteen years, with recent cohorts decreasingly living with roommates and instead lingering much longer in parents' households. To understand the sources and implications of this decline in independence, we estimate the contributions of local economic circumstances to the decision to live with parents or independently. Transition models, local aggregates, and state-cohort tuition patterns are used to address the likely presence of individual- and neighborhood-level unobserved heterogeneity. In regions where many students are exposed to college costs, we find that increased tuition is associated with more coresidence with parents and less living with roommates. Where fewer youth confront college tuition, however, local job market conditions are paramount in shaping the decision of whether to live with parents.
\end{abstract}

Key words: household formation, mobility, student loans

Lee and van der Klaauw: Federal Reserve Bank of New York (emails: donghoon.lee@ny.frb.org, wilbert.vanderklaauw@ny.frb.org). Bleemer: University of California at Berkeley (email: bleemer@berkeley.edu). Brown: Stony Brook University (email: meta.brown@ stonybrook.edu). This paper was previously distributed under the title "Debt, Jobs, or Housing: What's Keeping Millennials at Home?" The authors thank their referees, Andrew Haughwout and Henry Korytkowski; seminar participants at the Federal Reserve Banks of Boston and New York, the University of Virginia, and the Urban Institute; and conference participants at the Federal Reserve Bank of St. Louis, the Family Economics Workshop of the Barcelona GSE 2015 Summer Forum, the FDIC Consumer Research Symposium, Goldman Sachs' Millennials and Housing Day, New York University, and the University of California at Los Angeles' Ziman Center for Real Estate for valuable comments. The views expressed in this paper are those of the authors and do not necessarily reflect the position of the Federal Reserve Bank of New York or the Federal Reserve System. 
Recent cohorts of young Americans have, on average, extended their stays in their parents' households. After eventually moving out, their members return home to parents at higher rates. Climbing U.S. trends toward co-residence with parents are displayed in Duca (2014) for 1962-2012 and Matsudaira (2016) for 1960-2007. In this paper, we use millions of credit records from the Equifax-sourced Federal Reserve Bank of New York Consumer Credit Panel (CCP) to describe young Americans' residential arrangements from 2004-2015. Among 25-year-olds, we report an 11.4 percentage point increase in living with parents or similar elders and a 12.8 percentage point decline in living with groups of (similarly-aged) roommates. For these same years, several researchers document first stability and then a steep decline in young Americans' rate of homeownership. ${ }^{1}$ The dual trends of extended co-residence with parents and decreasing participation in rental and housing markets may contribute to slowed growth in both consumption and the housing market, as young people living "at home" delay major purchases and general entry into economic life.

This paper investigates the residence choices of young people in the Consumer Credit Panel, and their relationship to evolving local house prices, local employment conditions, and the cost of college for local students. We document upward trends in aggregate rates of co-residence with parents and other elders among 25-year-olds that are not only persistent but also widespread, with substantial increases in co-residence with parents in all 48 contiguous states. In addition, we discuss a range of co-residence measurement concerns and cite outside evidence suggesting a steep upward trend. ${ }^{2},{ }^{3}$

What are the likely consequences of lingering at home for young people's economic lives? Relatedly, what consequences might these trends have for the duration of the ongoing U.S. economic recovery? In order to answer these questions, we must understand the origins of the decline in independent living among American youth. Recent work on household formation, such as Dyrda, Kaplan, and Rios-Rull (2012), Duca (2013), and Matsudaira (forthcoming), has analyzed the link between an observed decline in household formation and changes in

\footnotetext{
${ }^{1}$ Agarwal, Hu, and Huang (2013), Brown and Caldwell (2013), Brown, Caldwell, and Sutherland (2014), and Brown et al (2015), the CFPB (2013), and Mezza, Sherlund, and Sommer (2014) report substantial declines in youth homeownership since 2007.

${ }^{2}$ See, for example, Mykyta and Macartney (2011).

${ }^{3}$ The link between homeownership and student debt has been examined in the PSID and the NELS 88 by Cooper and Wang (2014), in the SCF by Gicheva and Thompson (2014), in the 1997 cohort of the NLSY by Houle and Berger (2014), and in the CCP by Bleemer et al. (2017). Kurz and Li (2015) address the link between student debt and auto purchase.
} 
employment and poverty. Along with Matsudaira, Duca, and Dyrda, Kaplan, and Rios-Rull, our first candidate explanation for youths' increasing reliance on parents might be labor market difficulties. Following Agarwal, Hu, and Huang, we might next suspect that youth residence choices respond to local house prices. Finally, we and others have studied the unprecedented U.S. student debt climb that coincides with the trend toward living with parents. ${ }^{4}$ Figure 1 depicts the enrollment-weighted mean of public and private college and university tuition for each U.S. state and the District of Columbia from 2004 to 2015. College costs have risen steeply, with mean tuition across the states rising by $\$ 6576$, or 76 percent, over the period. If the financial burden of college is increasingly borne by students and families, we might also expect this to influence students' ability to live independently following school. To what extent, then, can we say that the observed climb in intergenerational co-residence coincides with economic challenges to youth such as weak job markets, costly housing, or high tuition?

Worth noting is that national labor and housing market trends display pronounced cyclicality, while co-residence with parents and college costs follow comparatively acyclical upward trends. Of course, these aggregates mask evolving local relationships among housing cost, labor markets, and youth residence choices. The fine geographic data, vast sample size, and long panel of the CCP allow us to observe the residence choices of large numbers of 25-yearolds at fine geographic levels, and to compare them over many birth cohorts. All of this allows us to study youth residence choices under a rich variety of economic circumstances. Our hope is that the resulting understanding of the origins of the decline in independent living yields insights regarding its relationship to existing policy, its potential consequences for young Americans' consumption and welfare, and its likely persistence or development in the future. While labor and housing market origins may suggest a cyclicality in the rate of co-residence with parents, college cost origins, given longstanding U.S. college tuition trends, may suggest an ongoing decline in youth independence.

In an approach that builds on Ermisch (1999) and Kaplan (2012), we model the fraction of young consumers who live with their parents, as well as the flows of young consumers into and out of parents' households over time, as a function of patterns in local unemployment, youth unemployment, house prices, wages, and the enrollment-weighted average college tuition

\footnotetext{
${ }^{4}$ See Brown et al. (2015a) and Dettling and Hsu (2014).
} 
confronting a given cohort in a given state. ${ }^{5}$ We address endogeneity concerns regarding the college spending of an individual student or family by estimating in state and county aggregates, and by providing direct estimates of the relationship between state-cohort tuition levels and subsequent co-residence. Our aim is to report intent-to-treat estimates of (an approximation of) the gross tuition amount a student would be charged for college should she attend, given her state and birth cohort.

Our estimates of the relationship among intergenerational co-residence choices and the economic conditions under which they are made reveal markedly different decision processes in regions where college is more and less relevant. In high college graduation rate regions, many young students are exposed to college costs, and jumps in the tuition facing a college cohort are met with extended periods of co-residence with parents, or more moving "home" in early adulthood. For example, a $\$ 1000$ increase in a state-cohort's mean college tuition is associated with a 0.72 percentage point increase in co-residence with parents. ${ }^{6}$ Given a $\$ 6202$ increase in mean tuition for the higher graduation rate states, tuition growth is able to account for 4.5 percentage points of their observed 10.5 percentage point growth in co-residence with parents at age 25 from 2004 to 2015 .

In low college graduation rate regions, fewer students confront college tuition, and local job market conditions, with particular emphasis on wages, are the dominant economic factor in young people's decision to live with parents. An increase of $\$ 100$ in average weekly wages is associated with a 3.9 percentage point decline in co-residence with parents among the lower college graduation rate states. ${ }^{7}$ What the high and low college graduation regions share in common is a secular trend toward intergenerational co-residence: in all cases, and with or without controlling for the levels or progress of economic circumstances, the coefficients we estimate on indicators for each calendar year reflect steep and approximately monotonic growth in intergenerational co-residence from 2004 to 2015. This growth is particularly pronounced among the lower college graduation rate states.

\footnotetext{
${ }^{5}$ Ermisch poses the question in the context of survey data on British youth of the 1990s, who made co-residence choices under very different economic and social conditions, and for whom college cost was of little relevance. Kaplan's study emphasized high frequency job shocks and residential transitions, and also did not address college costs.

${ }^{6}$ This coefficient estimate differs significantly from zero at the five percent level.

${ }^{7}$ This coefficient also differs significantly from zero at the five percent level.
} 
Analysis of the geographic sources of the estimated tuition-co-residence relationship indicates that their positive association arises primarily in the Northeast and Midwest, or, alternatively, in more urban settings. All of these estimates align with the broader claim that we observe a meaningful tuition-co-residence association where a greater share of youth attends college, and hence where a greater share of youth is exposed to college costs.

If young Americans are increasingly living with parents, one might ask what residential arrangements have fallen out of favor. Our estimates reveal declining secular trends in living with two or more roommates that approximately offset the climb in living with parents. Rates of living in couples or alone, controlling for economic factors, are comparatively stable. Estimates relating state-cohort college costs to residential arrangements show that the afore-mentioned $\$ 1000$ hike in tuition for youth in high graduation states is associated not only with a 0.72 percentage point increase in co-residence with parents, but also with a 0.86 percentage point drop in living with roommates, and little change in living alone or in couples. Hence youth in high graduation states facing greater college costs appear to be foregoing rooming with peers for the cost-saving option of living with parents.

Our transition model estimates of the rate at which American 23-to-25-year-olds move home to parents suggest a protective effect of strengthening local labor markets on the independence of youth. Here a one percentage point increase in local employment in the youth location is associated with a 0.2 to 0.3 percentage point decline in the rate at which youth move home to parents over the two years, and a $\$ 100$ increase in average weekly wages for the county over two years is associated with a 0.12 to 0.15 percentage point decline in the rate of moving home to parents. ${ }^{8}$ By and large, the economic determinants of moving away from parents, if they exist, are far less obvious. In contrast to the rate of moving home, we do not find a substantial or significant association between employment or house prices and the rate at which youth in the county who were living with parents at 23 achieve independence by 25 . The one meaningful association between economic growth and moving out is this: as wages rise in the parent location, youth living with parents are considerably less likely to move out.

Section I of the paper discusses the emerging literature on the recent changes in youth residence, and positions our paper within it. Section II describes the various data sources that we employ, particularly the CCP, which is comparatively novel. In Section III, we present new

\footnotetext{
${ }^{8}$ The employment and wage coefficient estimates are each significant at the one percent level.
} 
evidence from the CCP on the (rapidly evolving) residential circumstances of 25 -year-olds from 2004 to 2015. Section IV places this descriptive analysis of the data, and our subsequent empirical models of intergenerational co-residence patterns and the decision to move home or away, in the context of the existing theory of co-residence with parents developed by Kaplan (2012). Section V lays out an empirical model of the stock of youth living with parents, along with transition models of the flow to independence for youth living with parents and the flow back home to parents for youth living independently. Section VI reports estimation results, and Section VII offers some concluding thoughts.

\section{Related literature}

The existing literature emphasizes the relationship between employment conditions, or poverty, and intergenerational co-residence. Earlier work, including Goldscheider and DaVanzo (1985, 1989), Haurin et al. (1993), and Whittington and Peters (1996) establishes a longstanding pattern of greater youth co-residence with parents when economic circumstances are poor. More recently, Card and Lemieux (2000) demonstrate a noteworthy retreat home for Canadian youth in response to the prolonged Canadian recession of the 1990s. Dyrda, Kaplan, and Rios-Rull (2012) demonstrate a substantial influence of household formation responses to the business cycle on the Frisch elasticity of labor supply. Duca (2013) finds a close relationship between 1979-2013 time series on U.S. 18-64-year-olds' rate of co-residence with parents and U.S. poverty rates.

Two recent papers are particularly relevant to this study. Matsudaira (forthcoming) predates the analysis here, and considers the influence of local economic conditions on co-residence with

parents in the U.S. over both an earlier and a longer window. He uses cross-sectional Census and American Community Survey (ACS) data, available at varying intervals from 1960 to 2007, to examine the relationship between state-level employment and housing conditions and coresidence with parents over a 47-year period. Unlike our analysis, the paper is able to describe patterns in the relationship between state economic conditions over a very long period of time, which offers a better-informed picture of the potential role of social trends in living with parents. Further, it paints a rich picture of the (considerable) degree of demographic heterogeneity in coresidence patterns, a type of analysis which our administrative credit bureau data cannot support. Our study also offers some unique evidence, owing to its panel approach, fine geography, recent measures, range of residential outcomes, and introduction of college costs. By comparison, 
Matsudaira's data are cross-sectional, which restricts his analysis to coarse geography, for reasons discussed below. His estimation window stops short of the largest downturn confronted by U.S. youth in recent memory, and, finally, Matsudaira omits the cost of college. ${ }^{9}$

Student and other consumer debts, and their contribution to rising co-residence with parents, are the primary interest of Dettling and Hsu (2014). Their study and ours have developed concurrently and independently, using the same primary data source. The focus of the two papers, however, is quite different; one might see them as complementary. Dettling and Hsu are interested in the role of current individual debt levels and repayment, both in the decision to move home and in the youth's ability to recover from an economic shock and eventually regain independence. As such, their estimation provides new insights into the relationship between debt struggles - including, importantly, repayment struggles - and youth residence circumstances. These findings are of clear independent value when compared with the results reported in this paper (and vice versa, we believe). At the same time, current individual debt levels and delinquency or default status contain the accumulated history of employment, housing, and other shocks, and reflect past education choices. As such, estimated effects of, for example, realized student loan delinquency on the move home or the move away do not isolate student loan effects from, for example, the effects of recent job market fluctuations. Therefore Dettling and Hsu's estimates do not answer the specific question we pose in this paper regarding the separate contributions of debt, jobs, and housing to 25-year-olds' delayed independence, despite providing many novel and policy-relevant insights on debt and co-residence.

\section{Data}

\section{a. The FRBNY Consumer Credit Panel}

The FRBNY Consumer Credit Panel (CCP) is a longitudinal dataset on consumer liabilities and repayment. It is built from quarterly consumer credit report data collected and provided by Equifax Inc. Data are collected quarterly since 1999Q1, and the panel is ongoing. ${ }^{10}$ Sample members have Social Security numbers ending in one of five arbitrarily selected, randomly assigned pairs of digits. Therefore the sample comprises 5 percent of U.S. individuals with credit reports (and Social Security numbers). The CCP sample design automatically

\footnotetext{
${ }^{9}$ This is sensible, one might argue, given that the prevalence and balances of student loans were substantially lower over much of his estimation window.

${ }^{10}$ Student debt data are only available in the CCP starting in 2003.
} 
refreshes the panel by including all new reports with Social Security numbers ending in the above-mentioned digit pairs. Therefore the panel remains representative for any given quarter, and includes both representative attrition, as the deceased and emigrants leave the sample, and representative entry of new consumers, as young borrowers and immigrants enter the sample. ${ }^{11}$

While the sample is representative only of those individuals with Equifax credit reports, the coverage of credit reports (that is, the share of individuals with at least one type of loan or account) is fairly complete for American adults. Aggregates extrapolated from the data match those based on the American Community Survey, Flow of Funds Accounts of the United States, and SCF well. ${ }^{12}$ However, because we focus on young people's co-residence decisions, we restrict our dataset to 23- and 25-year-olds, which have lower coverage than later ages; coverage over 2003-2013, the era used in our Section IV-V estimates, ranges between 83.4 and 93.9\% for 25-year-olds, increasing from 2003 to 2007 and decreasing from 2007 to 2013 (compared to estimates from the US Census). ${ }^{13}$ Nevertheless, we do have some information about individuals not covered in the CCP; we know how many live in each state (based on Census figures), and we know that, in nearly all cases, they do not have conventional consumer debt or credit (in which case they would be covered by Equifax). We use this information to analyze and bound our estimates below. ${ }^{14}$

We construct a cohort-level dataset from the CCP by extracting a panel of all individuals who turn 23 or 25 years old in each year between 2003 and 2013. Because the time-series aspect of our study drastically increases the number of observations, we only pull a random 1\% sample of the covered U.S. population, instead of the full CCP 5\%. There are 546,824 25-year-olds in the dataset, of whom we have 1.01 million observations. ${ }^{15}$

\footnotetext{
${ }^{11}$ See Lee and van der Klaauw (2010) for details on the sample design.

${ }^{12}$ See Lee and van der Klaauw (2010) and Brown et al. (2015b) for details.

${ }^{13}$ We use the 2008 Census population projections as 'true' population data from 1999 to 2011 and the 2012 Census year-age population projections for 2012 and 2013. In each case, these are the most accurate available data on population size by age, year, and state.

${ }^{14}$ Lee and van der Klaauw (2010) extrapolate similar populations of U.S. residents aged 18 and over, overall and by age groups, using the CCP and the ACS, suggesting that the vast majority of US individuals at younger ages have credit reports. Jacob and Schneider (2006) find that 10 percent of U.S. adults had no credit reports in 2006, and Brown et al. (2015b) estimate that 8.33 percent of the (representative) Survey of Consumer Finances (SCF) households in 2007 include no member with a credit report. They also find a proportion of household heads under age 35 of 21.7 percent in the 2007 SCF, 20.64 in the 2007Q3 CCP, and 20.70 from Census 2007 projections, suggesting good representation of younger households in the CCP.

${ }^{15}$ Note that the panel data used in constructing some of the variables used in estimation contain roughly 10.1 million person-year observations.
} 


\section{b. Other data sources}

Table 1 summarizes the additional data that we use in our aggregate analysis of parental co-residence. All financial variables in the paper are measured in 2013 dollars. The first empirical model of co-residence we estimate below relies on data aggregated to the level of the state by year by cohort. The descriptive statistics in Table 1 report means across these cells in the pooled sample of aggregates. These descriptive measures of the pooled aggregates are noteworthy for their variability. While the average state-year-cohort has a ratio of employed residents to overall adult population of 57.54 percent, we also observe a standard deviation in employment among the states of 13.27 percentage points. State-year-cohort means for house price index, urban population, graduation rate, and tuition also vary widely in the pooled data.

Our next empirical specification estimates the relationship between the rate at which youth transition away from or home to their parents' households, and these are estimated using county-cohort-year aggregates. Columns (2)-(4) provide average two-year changes in each characteristic across county-cohort-year cells for three groups: all relevant youth, those living independently, and those living with parents. The most noteworthy differences between the locations of those living with parents and living independently are the more rapidly improving labor markets characterizing the counties of the independent youth, and the more rapidly growing house prices of the parent locations. This various measures taken from these data remind us of the problems that arise when we measure local economic conditions in parent neighborhoods for co-residing youth and youth neighborhoods for independent youth.

The annual county-level employment data are drawn from the Bureau of Labor Statistics' (BLS) Quarterly Census of Employment and Wages (QCEW) program. The unemployment data are reported on a quarterly basis, and they cover a total of 3,197 counties. In order to measure the employment-to-population ratio, we also draw annual county-level population data from the US Census's Population Estimates. ${ }^{16}$ We calculate the youth unemployment rate at the state level using employment data from 18- to 30-year-old individuals in the CPS, aggregated from months to quarters. ${ }^{17}$ Average weekly county-level wage data for 3,197 counties are drawn from the BLS's QCEW program.

\footnotetext{
${ }^{16}$ Data are from the 1990s Postcensal Estimates and the Vintage 2009 and 2014 estimates.

17 This aggregated sample of the CPS (over all months from 2003 to 2014) includes 3.2 million respondents between age 18 and 30 - 19,333 of whom are missing labor force status information - though due to the sampling
} 
House price appreciation values are calculated at the county level using data from the CoreLogic home price index (HPI). The CoreLogic HPI uses repeat sales transactions to track changes in sale prices for homes over time, with the January 2000 baseline receiving a value of 100. We aggregate an annual index to avoid seasonal variation. The CoreLogic data cover 1,266 counties (covering $89 \%$ of the 25 -year-olds observed in our sample) in all 50 states and the District of Columbia, but fail to cover some parts of rural America. ${ }^{18}$ In our regression analysis below, we include an indicator for whether the individual lives in a county populous enough to be covered by the CoreLogic HPI series. Its coefficient estimate goes largely unreported, but in each case is available from the authors. ${ }^{19}$

Several of our estimates require a measurement of the college graduation rate for a given cohort in a given state. We calculate the total number of graduates using the Integrated Postsecondary Education Data System (IPEDS), summing over the number of graduates of fouryear and two-year institutions who receive degrees within $150 \%$ of the normal completion time in that state-year. We calculate the average graduation rate as the ratio of the total number of graduates to the total number of 24-year-olds in the state, as estimated by the US Census. The mean graduation rate across states over our sample is 34.1 percent.

The analysis below also includes a set of college tuition measures. Ideally, we would like to track the cost of college in a given location for a given cohort while the cohort is between ages 18 and 22, and then attach it to the cohort going forward as an indication of the cost of college relevant to the cohort's decision-making. However, given our objective of estimating outcomes measured at ages 23 and 25, an age 18 to 22 tuition measure would require us to observe tuition seven years before the last-observed outcome for each cohort. The IPEDS data on which we rely for state tuition levels in each year are complete from 2000 forward. The CCP fourth-quarter outcomes we track are available through the end of 2015. A seven-year look-back for tuition would reduce our sample of 25-year-olds to the 2007-2015 window. In order to extend the sample backward into the pre-recession window, we have chosen to shorten the ages at which we measure tuition to ages 20 to 22. As a result, we estimate with a sample of 23-year-olds observed

methodology of the CPS, some people appear in the dataset twice (in two different quarters). Data are aggregated using individual weights.

${ }^{18}$ In our regression analysis below, we include an indicator variable for whether the individual lives in a county covered by the CoreLogic HPI series, though we do not report the corresponding estimated coefficients.

${ }^{19} \mathrm{We}$ also draw the median value of owner-occupied housing units by county in 2000 from the US Census, estimating county-level median house prices as the product of that and the CoreLogic series. These are employed in some footnoted analysis of the relationship of intergenerational co-residence to the level of house prices. 
from 2003 to 2013, and 25-year-olds from 2005 to 2015. We construct a series of state-cohort average sticker and net costs of public and private colleges by pulling cost data from IPEDS. ${ }^{20}$ We define sticker cost as the sum of tuition and fees (excluding room and board) at US colleges and universities, where net cost is sticker cost minus grant aid. Costs are averaged across postsecondary institutions by state, sector, and year, where weighting in the averages is based on each institution's share of undergraduate enrollment.

Our decision to study sticker, and not net, prices of college in estimation sections $\mathrm{V}$ and VI is guided primarily by one concern. Grant aid in a given year in a given state is shaped by many factors, among them the financial need of the students. Hence any estimate of the association between net tuition and youth residence outcomes would conflate true college cost effects with effects of the economic conditions of college students' families. Perhaps in part for this reason, we find that estimating with net tuition leads, in many though not all cases, to large and precise estimates of tuition-residence relationships. Net tuition results are available from the authors.

\section{Aggregate trends in young consumers' residence choices}

\section{a. Co-residence with parents: measurement and trends}

Each observation in the CCP includes the (anonymized) information in an individual's credit report at the end of that quarter (e.g. zip code, birth year, total balances of 10 types of consumer debt, etc.) as well as the information in the credit reports of all members of that individual's household, where households are defined by street address (down to an apartment number). ${ }^{21}$ These data lead us to define co-residence (with parents) to be the circumstance in which a young person (here a 23- or 25-year-old) resides at the same street address as at least one (Equifax-covered) individual who is between 15 and 45 years her senior, without regard to household head status or the relationship between the household members. ${ }^{22}$ Data from the Center for Disease Control and Prevention's (CDC) National Vital Statistics System show that, for the 1978 and 1988 birth cohorts (the early and late ends of our sample), almost all mothers

\footnotetext{
${ }^{20}$ IPEDS covers all 7,255 postsecondary schools in the United States, 5,126 of which provide enrollment and tuition data, accounting for 97.8 percent of enrollment in the dataset.

${ }^{21}$ See Avery et al. (2003) for a detailed discussion of the contents, sources, and quality of credit report data.

22 We exclude household members with empty credit files, as those individuals' addresses may no longer be accurately recorded by their creditors, or thereby by Equifax itself.
} 
and the vast majority of fathers were between the ages of 15 and 45 at the child's birth. ${ }^{23}$ Moreover, we define individuals who live in households of more than 10 people $(3.7 \%$ of 25 year-olds and $3.6 \%$ of 30-year-olds) as not co-residing, because most situations in which one would live in such a large household (prison, military, mobile home community) are not such that the individual is in her parents' household. ${ }^{24}$ Note that our definition might overestimate the aggregate rate of co-residence with parents due to a possible lag between a young person's switching his home address and updating his credit report address (as reported by financial institutions), which might bias the aggregate co-residence rate upwards. ${ }^{25}$

In order to evaluate the success of our measure of parental co-residence, we use the 20032012 Current Population Surveys to estimate the fraction of individuals who would fall under our definition of "living with parents" who are actually co-residing with parents (or other older relatives). ${ }^{26}$ We find that, in 2010, 92.6 percent of 25-year-olds whom we designate as 'living with their parents' either certainly or most likely co-reside, suggesting that we slightly overestimate co-residence in our analysis below. First, 84.0 percent live with their parents or similar elders: most commonly their parents themselves, but also their spouse's or partner's parents, or the parents of a sibling or in-law, their foster parents, their grandparents, or a parent's unmarried partner. Another 8.6 percent of 25-year-olds that meet our CCP definition of living with parents in 2010 most likely co-reside with elder relatives, but the CPS leaves their designation unclear; they may live with an older sibling, older relatives from outside of the nuclear family, or with a friend and the friend's parents. The remaining 7.3 percent of 25 -yearolds in 2010 who meet our CCP criteria for co-residing with parents actually do not co-reside with parents or elder relatives. 1.8 percent of 25 -year-olds who "live with their parents" actually live with older spouses; other, smaller groups are observed to live at the same address as an older landlord, an older roommate, or an older roomer. Roughly one percent of cases are either miscodes or exceedingly complex scenarios.

\footnotetext{
${ }^{23}$ The birth rate for women aged 45-49 in 1978 and 1988 was 0.2 live births per 1000 women. The birth rate for women aged 10-14 in 1978 (1988) was 1.2 (1.3) per 1000. The birth rate for men aged 45-49 in 1978 (1988) was larger, at 5.8 (7.1) per 1000. However, this remains quite small relative to the men's age 25-29 birth rate of 120.0 (111.1) per 1000.

${ }^{24} \mathrm{We}$ also assume that individuals whose address is listed as a post office box do not co-reside (4\% of 25 -year-olds, and $5 \%$ of 30 -year-olds).

${ }^{25}$ Transition model estimates of the probability that independent youth move home in Sections V-VI are less susceptible to lagged address updating concerns.

${ }^{26}$ Our total sample size is 207,928 25-year-olds and 210,711 30-year-olds across the ten years of our analysis. We use sample weights in order that our analysis is nationally representative.
} 
Importantly, our CPS analysis shows that the rate at which we overestimate 25-year-old co-residence is unchanging over time. The fraction of 25 -year-olds that we categorize as "living with their parents" who co-reside with a parent or elder relative was bounded between 91.6 and 92.6 percent from 2003 to 2012, and we find no evidence of either a linear or quadratic time trend at the $10 \%$ level of significance. This provides evidence that our trend analysis below, in both the stocks and flows, is unbiased despite slightly overestimating the fraction of young people who live with their parents (or in similar living arrangements) at any fixed point in time.

Figure 2 depicts the proportion of U.S. 25-year-olds living with "parents" in the CCP from 2004-2015. ${ }^{2728}$ For 25-year-old CCP sample members, we observe an increase in the rate of co-residence with parents or similar elders from 33.5 percent in 2004 to 44.9 percent in 2015. ${ }^{29}$ Note that this pattern is free of life-cycle effects, as we measure co-residence with parents for the cross-section of CCP sample members who are 25 years old in each year. This substantial growth in living with parents is approximately monotonic over the period, and proceeds at a steady pace. Overall, the rate of co-residence with parents observed in the CCP grows by 11.4 percentage points for 25-year-olds over our 2004 to 2015 window.

Figure 3 extends these results by examining the increased prevalence of parental coresidence at the state level..$^{30} \mathrm{We}$ find that parental co-residence among 25 -year-olds increased in all 48 contiguous states in the decade between 2003 and 2013 (though it slightly decreased in Alaska), with a median increase of 13.8 percentage points. Heterogeneity in parental coresidence is quite large across states, with state-level co-residence rates for 25-year-olds ranging from 30 percent to over 50 percent in 2012-2013. States in the center of the country (Rocky Mountain and Great Plains states) experienced the least growth in parental co-residence, while

\footnotetext{
${ }^{27}$ In the CCP, we observe individuals' birth years, but not their birth months. The median individual born in a year turns 25 around July $1^{\text {st }} 25$ years later. In order to capture the average characteristics of 25 -year-olds in a year, then, we use the observations of those born 25 years earlier from the first quarter of the following year, allowing for a six month lag in order to measure characteristics, on average, in the middle of the year in which the individual is 25 , and a one-quarter lag from the median time at which those individuals would be 25.5 years old to account for delays in Equifax data updating, in which loans typically first appear in the data about one quarter later than the origination date.

${ }^{28}$ Importantly, intergenerational co-residence is a viable means of responding to labor or housing market shocks, or general financial strain, mainly for the subset of families living close enough to each other for the move not to be exceedingly disruptive. We would prefer to estimate in this population, but are unable to identify parent locations in families in which youth remain independent. We thank a referee for this observation.

${ }^{29}$ From this point we adopt the phrase "living with parents" to describe youth living with parents or with one of the variety of responsible elders captured by our co-residence measure.

${ }^{30}$ This analysis is enabled by the massive size of the CCP data set; our analysis includes at least 16625 -year-olds in each year-state presented in Figure 3, with a median of 1,282 individuals per state-year.
} 
states in the Northeast and West Coast experienced the sharpest increases, some by more than 20 percentage points between 2003 and 2013. Overall, a striking change appears to have occurred since 2004 in the living arrangements of young consumers. ${ }^{31}$

Of course, others have documented a large and ongoing change in intergenerational coresidence in the U.S., either over earlier periods of time or for very recent years and in parallel to this study. Their findings using long-standing surveys provide us with an opportunity to validate our measures of intergenerational co-residence in the comparatively novel, entirely administrative Consumer Credit Panel. Briefly: our estimates of the national rate of intergenerational co-residence are quite close to rates reported by Matsudaira (2016) using the 2000 Census, and by Paciorek (2014) and by Dettling and Hsu $(2014,2015)$ using CPS data for some or all of 2000-2013. In the appendix to this paper, we give a detailed description of the coresidence rate estimates in Matsudaira, Paciorek, and Dettling and Hsu, and compare them to our own co-residence trend estimates.

In sum, we observe a steady growth in co-residence with parents among U.S. youth. While the level of co-residence rates may be sensitive to measurement choices, the levels and trends we obtain are similar enough to the findings of other recent researchers using alternative methods and established survey, rather than administrative, sources to suggest that our CCP measures are informative. All sources and methods discussed in this paper point to two empirical facts: co-residence with parents was common in 2004, and it is substantially more common today.

\section{b. Trends in other living arrangements}

Given general agreement that young Americans are staying home with parents at an increasing rate, what living arrangements are they casting aside? Popular speculation suggests declining rates of first marriage among young people in the wake of the recession. After the release of the 2009 American Community Survey, Mather and Lavery (2010) noted a recession-

\footnotetext{
${ }^{31}$ This trend could be determined in part by social or demographic phenomena, rather than economic pressures. However, while the number of Americans aged 45-64 increased by 24 percent from 2002 to 2012 (according to the U.S. Department of Health and Human Services' Administration on Aging), the lifetime number of children per woman remained near two and, if anything, was very slightly increasing from 1970 to 2010 (Population Reference Bureau 2012). We thank a referee for this observation. It is unclear, then, the extent to which changing demographics on their own can be expected to generate large changes in the rate of co-residence with parents. Nevertheless, in the interest of accounting for possible social and demographic changes, we allow for a flexible time trend as we model the stock of co-residence below.
} 
era decline in the share of young people who had ever been married. Shortly after, Wolfers (2010) countered that this data artifact represented not a meaningful decline in stable relationships, but an ongoing increase in the age at first marriage in the U.S., coupled with an increase in cohabitation during the recession, which may have been motivated by a desire to cut living expenses. One relevant question for the current study, then, may be whether young Americans are choosing extended adolescence at home with parents in place of independent adulthood and marriage.

We categorize individuals who are not co-residing with parents into three types. An individual is defined as living alone if he is the only (Equifax-covered adult) resident at his street address. We then divide the remaining individuals into those who live with only one other person and those who live with more than one other person, excluding households with more than 10 people and individuals whose report lists a post office box address. ${ }^{32}$

Figure 4 shows CCP trends from 2004 to 2015 in the rates at which 25-year-olds appear alone, with parents, with one adult of similar age, and with two or more adults of similar age. ${ }^{33}$ The latter category we interpret as living with roommates.

The growth we observe in co-residence with parents appears to come at the cost of fewer young people living with roommates. We calculate a decline in the rate at which 25 -year-olds live in groups of roommates from 32.5 percent in 2004 to 19.7 percent in 2015. Meanwhile, the rates of living in couples and living alone are comparatively stable. Hence the evidence in estimation Table 4, below, will not particularly fall in support of a claim that American youth prolonging their stays with parents are postponing traditional milestones of adulthood. They may, however, be giving up independent years of living with groups of friends for the costsaving benefit of years at home with parents.

\section{c. Trends in tuition}

${ }^{32}$ Our CCP data do not allow us to measure the rates at which CCP sample members are marrying before and after the recession. They do not even allow us to measure cohabiting relationships, whether or not they involve marriage. What we can do, however, is look at trends in the rate at which young Americans co-reside with one other adult of a similar age. The benefit of this approach is that it includes marriage along with both opposite sex and same sex cohabitation, yielding a broader picture of trends in co-residing relationships over the period. The obvious drawback, however, is that it includes roommate pairs whose relationships are platonic. Our analysis of CPS household characteristics suggests that residing with one adult of similar age is a reliable predictor of romantic cohabitation. (These results are available from the authors.) Interpretation of trends in living with a single adult roommate of comparable age should, however, bear this inclusion in mind.

${ }^{33}$ By similar age, we mean 14 or fewer years older, or any amount younger, than the 25-year-old file holder. This cutoff is chosen to create mutually exclusive and exhaustive living arrangement categories. 
College costs in the U.S. have been rising steadily for decades. As described previously, Figure 1 depicts the enrollment-weighted public and private college and university mean tuition and fees for each state in every year from 2001 to 2013. Each dot represents a state-year. Each color of dot represents a single state. The figure demonstrates a climb in state tuitions: in our estimation sample of state-cohort-years, we observe a mean tuition growth of 75.9 percent between 2004 and 2015, from $\$ 8659$ to $\$ 15,235$. Figure 1 further demonstrates a meaningful expansion in the cross-state dispersion of states' mean tuitions from early to late in the estimation window. And, finally, tracking states' color-coded dots from year to year generates an understanding of the intermittent nature of jumps in real college tuitions, with the year-to-year tuition-setting decisions of state boards of regents leading several states to leap-frog each other in the cross-state tuition ranking each year.

Our empirical approach in Sections V and VI relies on these unpredictable jumps in real tuition within states for informative variation in the college costs facing individual students. Further, our approach identifies tuition effects based on within-state dynamics while also removing the overall positive trend in the national mean of tuition, as well as its nonlinear movements from year to year. We discuss our identifying assumptions, and states' tuitionsetting, in more detail in Subsection $b$ of the Appendix.

As a first pass at local analysis of the relationship between college costs and intergenerational co-residence, Figure 4 presents suggestive evidence of an association between student debt and parental co-residence in a simple state-level scatter plot that relates the 20082013 change in the rate of parental co-residence among 25-year-olds in a state to its 2008-2013 change in student debt per graduate. ${ }^{34}$ The regression line in this simple scatter plot reflects a positive 2.9 percentage point increase in co-residence with a $\$ 10,000$ increase in student debt per graduate.

\section{Job market, house price, and tuition effects on intergenerational co-residence from a theoretical perspective}

We rely on Kaplan (2012) for a theoretical description of the dynamic game played between a parent and child over the choice of separate or shared residence and the child's labor

\footnotetext{
${ }^{34}$ The chart looks qualitatively similar when constructed from 2003-2013. We isolate the post-recession window as it is characterized by particularly active changes in states' public college tuitions.
} 
market activities. The child chooses consumption and saving, labor supply (or, where relevant, job search), and whether to live independently or with his parent. The altruistic parent, in turn, allocates a fixed income stream among private consumption, public household consumption, and a financial transfer to her child.

In Kaplan, the manners in which the child benefits from co-residence with the parent are the following: (i) a child who co-resides with his parent pays no rent or mortgage, and (ii) when the parent and child co-reside, they each enjoy the public household good. The cost to the child of co-residence enters as a preference shifter. Hence the benefits of co-residence appear through the child's consumption, and decline along with the marginal utility of consumption, while the cost of co-residence remains fixed as consumption grows. It is this mechanism that generates a tendency toward independence as the earnings and assets of the child rise.

Comparative statics for co-residence arising from the model for the relationships at issue in this paper are fairly straightforward. Kaplan describes them as follows on pages 472-473: "Youths are more likely to live away from home when earnings, assets, or the value of independence is higher. However, the probability of living away from home is ambiguous with respect to parental income. On the one hand, higher parental income generates higher parental transfers and hence a lower earnings/assets threshold for the youth to live away. On the other hand, higher parental income means higher consumption in the parental home, making living at home a more attractive option for the youth." These predictions for the relationship between child earnings and co-residence with a parent, and between parent income (or assets) and coresidence with a child, are helpful in interpreting our estimates of the association between local labor market characteristics and co-residence below. ${ }^{35}$

Further, as housing costs in the model are paid in any case by the parent but by the child only in the event that he child lives independently, the model easily predicts that, all else equal, a

\footnotetext{
${ }^{35}$ Kaplan (2012) estimates the relationship between state-level job market conditions and the share of youth living with their parents in early adulthood. Our empirical analysis may be differentiated from Kaplan's own (earlier and influential) estimates for its coverage of youth choices from 2011 to 2015, in addition to the 2000s, and for its addition of college tuition to the set of factors that may shape co-residence. Further, Kaplan estimates co-residence transition responses to individual youths' realized job losses using the NLSY-97, but must cope with the potential endogeneity of job loss to moving home. Owing to data that are unusual in that they permit panel tracking of the fine geographic locations of millions of consumers, we are able to estimate the response of co-residence transitions to arguably exogenous shocks in local labor and housing market conditions. Of course, our analysis lacks Kaplan's careful treatment of the insurance role of the option of moving home to parents, and his structural estimation of the high-frequency residential dynamics of the family as the child weathers positive and negative job market shocks.
} 
higher cost of housing may induce the family to co-reside. We relate this prediction to our house price estimates below.

While the child's current assets enter the Kaplan model, the model does not address human capital or past educational investments or costs. One simple way of adapting the framework for our purposes is to assume that the influence of past college tuition appears in the child's current assets and wages. To fix ideas, consider an extension of the model in which, before entering the labor market, the child makes the simple binary decision to attend and complete college, at a price equal to the prevailing college tuition, or not to attend college. Following schooling the child enters the Kaplan model as written. Consider the co-residence effect of a tuition increase under these assumptions. For an increase small enough that the child's college entry choice is unchanged, the effect of the tuition increase on the post schooling circumstances is simply a reduction in the child's assets. For a tuition increase large enough to change the child's college entry decision, the effect is both an increase in assets, as the child avoids paying tuition, and any decrease in wages that results from reduced post-schooling human capital.

What are the predictions of this modified Kaplan model for the relationship between tuition and the child's post-schooling decision to live with parents or independently? As written, the direction of the effect is ambiguous. However, Bleemer et al. (2017) precisely estimate a small and insignificant response of college enrollment and graduation, and of years of schooling, to college tuition for a population comparable to the one we study in this paper. If the demand for college is truly price inelastic, then, in the context of our modified Kaplan model, the effect of a tuition increase will simply be to decrease the assets of a child who chooses college. Moreover, the tuition increase will have no effect on a child who does not choose college. Hence our simplistic modification of the Kaplan (2012) model predicts a negative effect of past college tuition on present co-residence with parents for youth who attended college, and no effect of past tuition on co-residence with parents for youth who did not attend college. Guided by this prediction, we estimate the tuition-co-residence relationship in groups with more and less exposure to college tuition in Section VI.

\section{Empirical model}

a. Stock of young people living with parents 
Next, the fine geographic data and long panel of the CCP allow us to exploit time variation in local economic conditions and student debt reliance to learn far more about the contributions of jobs, housing costs, and the cost of college at the local level to the decisive aggregate trend toward parents, and away from economic independence, that we observe for recent cohorts of young adults. This section presents three empirical models of parental coresidence. First, we describe a lagged stock model explaining the co-residence decisions of 23and 25-year-olds as a function of local unemployment, youth unemployment, house prices, and the enrollment-weighted average college tuition that applies to the state-cohort pair in question. This approach provides an informative description of the times and places in which parental coresidence is and is not common. Further, heterogeneity analysis allows us to examine the factors associated with co-residence across the country, and for more and less highly educated, and more and less urban, areas.

We estimate a state-level model of the share of young residents who are living with parents as a function of local socioeconomic conditions. In anticipation of the flow model to come, we consider individuals at two ages, 23 and 25. Define $Y_{\text {cst }}$ as the share of cohort $c$, state $s$, time $t$ youth who co-reside with parents. We model the share of co-resident youth as a function of the conditions in the state one year earlier, as well as state fixed effects to control for unobserved differences in culture and policy that do not vary over time. ${ }^{36} \mathrm{We}$ thus estimate the simple fixed effects model:

$$
Y_{c s t+1}=X_{c s t} \beta+Z_{c s} \gamma+\delta_{s}+\tau_{t}+\varepsilon_{c s t}
$$

where $X_{\text {cst }}$ represents a vector of cohort $c$, state $s$, period $t$ characteristics, the levels of which may influence the residence choices of the youth of state $s$ at $t+1$. This vector includes state-level QCEW wages and employment to population ratios, state-level youth unemployment based on our calculations in the CPS, and state-level CoreLogic home price indices. The vector $Z_{c s}$ represents characteristics of cohort $c$ and state $s$ that do not vary over time, which in this case are the enrollment-weighted average public and private college and university tuition prevailing in

\footnotetext{
${ }^{36}$ Hence the lagged regressors are observed when the estimation sample youth are 22 and 24.
} 
state $s$ when cohort $c$ was between the ages of 20 and 22, as described in Section II above. ${ }^{37}$ Realized individual educational spending may contain confounding individual (observed and unobserved) characteristics. ${ }^{38} \mathrm{We}$ address this concern by estimating using a measure of the cost of college for the state-cohort that is comparatively free of contributions from individual student ability, diligence, and other factors that shape realized educational attainment. Further, we include a vector of state fixed effects, denoted $\delta_{s}$, and time fixed effects, denoted $\tau_{t}{ }^{39}$ Idiosyncratic error $\varepsilon_{c s t}$ is clustered at the state level.

In implementing empirical model (1), we weight each observation by the age-25 population of the state. Though estimating in state aggregates without the population weight changes some of the many stock model estimates described below, it is generally true that the qualitative results are typically similar in weighted and unweighted specifications. Regarding the estimated coefficients on average tuition, one broad observation we have made in estimating a variety of weighted and unweighted specifications is the following: Some of the largest tuition swings over our estimation period belong to the smallest states. This may be one reason that the estimated tuition coefficients tend to be considerably more pronounced under the unweighted approach. Throughout Section III, we report population-weighted estimates. Unweighted estimates are available from the authors.

State-cohort-year average tuition is included in expression (1) as an exogenous measure of the cost of college for the population whose residential outcome we are estimating. In subsection $b$ of the appendix to this paper, we describe the identifying assumption we make regarding the

\footnotetext{
${ }^{37}$ The assumption underlying this approach is that the cost of college when a student reaches college age affects decisions at that point and far into her adulthood. However, the current cost of college in the state is likely to have little influence on the current residence choices of a 25 -year-old who has long since left school.

${ }^{38}$ Though we estimate the relationship between college costs and post-schooling co-residence with parents, much of the relevant literature relates student debt to post-schooling economic circumstances. Gicheva and Thompson (2014) discuss a student debt endogeneity concern in a related context. Heterogeneity in family generosity tends to bias the student debt coefficient in a co-residence regression downward, as generous families both impose less student debt and tolerate more co-residence. Lochner, Stinebrickner, and Sulemanoglu (2013) demonstrate a strong positive relationship between family support and student debt repayment in recent data on Canada's student loan system. On the other hand, individual-level student debt is closely tied to the student's level of educational investment. Lochner and Monge-Naranjo (2012) model the relationship between the nature of the schooling investment and the credit extended to students, with implications for the individual-level association between student debt and post-college labor market success that are of obvious relevance here.

39 One concern the estimation confronts is the possibility of a non-economic, social trend in the acceptability of intergenerational co-residence that may, in part, drive the growth in co-residence. However, the 2014 wave of the Federal Reserve Board of Governors' Survey of Household Economics and Decision-making (SHED) shows that the 64 percent of 2014 SHED families living in "doubled-up" households do so primarily for financial reasons. Only one in seven are doing so, at least in part, for the purpose of caregiving (Board of Governors 2015).
} 
exogeneity of state-cohort tuition shocks, and we marshal supporting evidence for this assumption.

We choose to estimate the stock relationship between local economic conditions and coresidence choices at a high level of geographic aggregation, the state, for a variety of reasons. Most important to us is the fact that aggregate analysis minimizes any endogeneity that might arise from young people's mobility. If there are systematic economic differences between the regions where young people live independently and the regions where their parents live, then the economic characteristics we measure in the young person's observed location may be endogenously determined by her co-residence decision. Assume, for example, that housing prices are higher in parents' neighborhoods than in children's neighborhoods, in keeping with typical life-cycle patterns of consumption in the U.S. Then the problem with the location of measurement generates a spurious positive relationship between local house prices and living with parents. By aggregating to the state level, we average across smaller geographic areas (like zip codes and counties), abstracting away from most mobility concerns. ${ }^{40}$

\section{b. Flow home to parents from independent living}

Nevertheless, one would certainly prefer to exploit the extensive variation in economic conditions that occurs below the state level in order to generate the most informative picture possible of youth residence choices. With a detailed panel on the repeated location choices of millions of early twentysomethings, in this study we are able to push the analysis to a finer geographic level.

To do so, we model the flows of children into and out of parents' households. We separate our baseline sample into youth who live independently in the initial period and youth who live with parents. This allows us to estimate the effect of more finely measured local economic conditions on co-residence transitions for samples in which the measure of local conditions is uniform: we estimate the effect of (changes in) local economic conditions in the parents' location on the rate at which dependent youth move out, and, separately, the effect of local economic

\footnotetext{
${ }^{40}$ Most moves to and from parent households occur within a state. According to Molloy et al. (2014), while 19.1 percent of CPS 20-24 year-olds moved between counties over the course of a year, based on pooled data for 20002012, only 3.3 percent of the 20-24 year-olds crossed state lines. Note further that the cross-state move rate declined over the period. Brown, Grigsby, van der Klaauw, Wen, and Zafar (2015) find that, among CCP individuals observed at age 18, only 12.82 percent had moved across state lines seven years later. Matsudaira (forthcoming) employs a similar state-level strategy, presumably owing to similar measurement concerns.
} 
conditions in the independent youth location on the rate at which independent youth move home. This approach also allows us to ask whether the effects of local economic conditions on whether a child moves away from home differ from the effects of those same conditions on whether a child moves back home.

This solution is appealing for economic circumstances that evolve over time and are relevant to youth residence choices in an ongoing manner. It is less helpful for the question of the relationship between the cost of college and later co-residence with parents for two reasons. First, for most young consumers, college costs are borne at only one point in the life-cycle. Tuition increases that develop after a youth leaves school are, by and large, irrelevant to the student. Second, tuition averages in our data vary primarily at the level of the state-cohort, as most college students attend public colleges and universities, and public college and university tuitions tend to move in response to a shared state legislative and budgeting process. Hence the CCP's panel dimension, and our transition models, may illuminate the relationship between (more) local economic conditions and co-residence with parents or independence and yet add little to our understanding of the relationship between college costs and co-residence. For the latter, we rely on stock model estimates.

Since we model two-year flows of parental co-residence between the ages of 23 and 25, we no longer lag the geographic characteristics by a year in identifying their effect on parental coresidence. Instead, in most instances, we estimate the dependence of the rate of moving home or away on the change in conditions over the two-year estimation window in the youth's initial location. However, college tuition in the youth's location from age 20 to 22 is a time-fixed characteristic. Hence we adopt two approaches to the estimation: in one specification, we estimate models of the dependence of transitions into and out of co-residence on the changes in local conditions over time, leaving out the time-fixed factor of interest, college cost. In addition, we report estimates based on an alternative specification, in which we allow co-residence transitions to depend also on the time-fixed tuition level relevant to the state-cohort, permitting these characteristics to influence the transition probability through their level at $t$ rather than through their (null) flow from $t$ to $t+1$. $^{41}$

\footnotetext{
${ }^{41}$ An alternative specification of our model including level measurements of all covariates is available from the authors. Given that the level of co-residence at time $t$, and hence the size and nature of the co-residing population, is shaped by past tuition, the influence of past tuition on co-residence transitions from $t$ to $t+1$ is unclear. Our Section
} 
Consider first the decision to move home to parents. From this point, we estimate intergenerational co-residence decisions aggregated at the county level. ${ }^{42}$ Maintaining the definitions above, we estimate a model of the share of independent youth in county $l$ (for "location") who move home between the ages of 23 and 25, $Y_{l t+1}^{H}$, in a sample of CCP youth who lived independently at age 23 , which we denote as time $t^{43}$

$$
Y_{l t+1}^{H}=\left(X_{l t+1}^{H}-X_{l t}^{H}\right) \beta^{H}+Z_{c l}^{H} \gamma^{H}+\delta_{s(l)}^{H}+\tau(t)+\varepsilon_{l t}^{H},
$$

Here superscript $H$ denotes factors influencing the probability of moving "home". Time-varying local regressors $X_{l t}^{H}$ include county-level average wages, employment to population ratio, and house price index. As mentioned above, we estimate the flow models with and without timefixed tuition, $Z_{c l}^{H}$. In addition, in these flow equations, our baseline $X_{l t}^{H}$ includes a linear national time trend, which is a constant when differenced. Further, we allow a vector of state-level fixed effects in the probability of moving home, $\delta_{s(l)}^{H}$, which may be interpreted as state-level time trends in co-residence. Importantly, in the flows home, location (county) $l$ is defined as the child's location away from home at time $t$, and all local characteristics at $t$ and $t+1$ are measured for location $l$.

Finally, though the modified Kaplan model described in Section IV does not predict a time dependence of co-residence transitions, apart from a response to the evolution of wages, employment, and housing costs, social developments may shift the level of the preference for coresidence over time, generating movements in the national flows home or away. Therefore we estimate under three separate approaches to the dependence of co-residence growth on the calendar year. First, we estimate under the assumption that $\tau(t)=0$. This approach adds nothing

IV modified Kaplan model, for example, would generate an ambiguous prediction for the direction of this relationship.

${ }^{42}$ Note that expression (2), below, does not push the data to the individual level. All of the regressors we consider are measured in local aggregates. While these local aggregates will have substantial predictive power for locally aggregated cross-sectional co-residence measures and co-residence transitions, without relevant individual-level exogenous covariates, which for this problem are limited in general and especially limited in the CCP, we have little hope of identifying which residents of a local area will move. We find that the magnitude and significance of labor market, housing, and student debt coefficients estimated based on the analogous individual-level co-residence transition models are very similar to those of the coefficients estimated using aggregate expression (2). The shortcoming of the individual-level analysis is evident in its modest R-squared values, as we identify the local moving rate rather reliably, but have little information with which to predict exactly who moves.

${ }^{43}$ The elapsed time from $t$ to $t+1$ is two years. 
to the above-mentioned state-level trends in co-residence with parents. Second, we allow a linear national time trend in the growth in co-residence, so that $\tau(t)=\tau^{h} t$. Third, we estimate the model adding a full set of year-specific fixed effects, so that $\tau(t)=\tau_{t}^{H}$. In this final specification, in addition to the above state trends, we allow a separate intercept for the rate of growth of parental co-residence in each year. This last specification might seem to involve excessive flexibility in the time dependence of the transition path. Though the first and second approaches are far easier to interpret in the context of the model discussed in Section IV, we include it in the interest of thoroughness.

\section{c. Flow away from parents to independent living}

We estimate a similar model for the share of county youth living with parents who move out between periods $t$ and $t+1$. The expression for the state fixed effects model estimated, using county-level aggregates is

$$
Y_{l t+1}^{A}=\left(X_{l t+1}^{A}-X_{l t}^{A}\right) \beta^{A}+Z_{c l}^{A} \gamma^{A}+\delta_{s(l)}^{A}+\tau^{A}(t)+\varepsilon_{l t}^{A},
$$

where all arguments are defined analogously to those in expression (2). In this case, all location characteristics are measured for location $l$, the parent's location in period $t$. Superscript $A$ denotes factors influencing the probability of moving "away". 44

As in the case of moving in with parents, we estimate expression (3) first including only the growth regressors, as well as the specified state and time effects. We then report estimates that add time-fixed tuition averages relevant to the state-cohort youth while college aged. In doing so, we note that the predictions of the modified Kaplan model discussed in Section IV for the direction of the relationship between college costs and the rate of moving away from parents among the resulting group of co-resident youth some years after college are ambiguous. As in the transition home case above, we estimate the transition to independence model using three specifications of time dependence. We estimate first assuming $\tau^{A}(t)=0$, then $\tau^{A}(t)=\tau^{A} t$, and, finally, $\tau^{A}(t)=\tau_{t}^{A}$.

Standard endogeneity concerns deriving from observable and unobservable individual and local characteristics that are fixed over the two-year window are accounted for by the transition approach we take to estimation. Obvious examples include child ability, parent generosity, and

\footnotetext{
${ }^{44}$ Owing to the unobservability of locations not chosen, what we will not be able to explore is the dependence of the youth's decision to move home on the characteristics of the parent's location, and the dependence of the youth's decision to move out on the characteristics of the youth's preferred independent location.
} 
persistent regional characteristics. Some remaining endogeneity concerns arise from the association between youth mobility and local house price and employment aggregates. By and large, they work against the main results described below. They are discussed in the appendix.

\section{Results}

\section{a. Stock of young people living with parents}

Table 2 reports the coefficient estimates for the stock parental co-residence model in expression (1) for 23- and 25-year-olds. Our baseline specification is shown in column (1), which includes each of the covariates listed in section $\mathrm{Va}$ as well as state dummies to control for unobserved permanent cross-state differences in culture and policy and year dummies to account for time-varying aggregate conditions, such as credit market conditions. ${ }^{45} \mathrm{We}$ find, as expected, that geographic areas with higher average wages are characterized by substantially lower rates of intergenerational co-residence: a $\$ 100$ greater mean weekly wage observed for the state and year in question is associated with a 2.1 percentage point decline in the share of 23- and 25-year-olds living with parents, and this coefficient is significant at the one percent level. ${ }^{46}$ Despite this substantial wage result, we estimate little association between either the overall employment to population share or the youth unemployment rate and the rate of co-residence in the state for the year. A once percentage point increase in employment is associated with a 0.03 percentage point decline in co-residence, and a one percentage point increase in youth unemployment is associated with a 0.06 percentage point increase in co-residence. The direction of each coefficient estimate matches our expectations, but neither is significant or of economically relevant magnitude. In sum, the job market results for the full population of state-years indicate that co-residence is particularly prevalent in lower-earning regions, and yet not closely tied to employment rates.

At the same time, we find a modest negative association between house prices and coresidence. The coefficient on CoreLogic house price index is -0.013 , and is significant at the ten percent level. This indicates that a one standard deviation difference in house price index for the pooled 2003-2015 sample of states is associated with a 0.53 percentage point lower rate of coresidence with parents among 23- and 25-year-olds. One might consider this a precisely

\footnotetext{
${ }^{45} \mathrm{We}$ thank a referee for the observation that credit access common across states varies widely over this period and may affect co-residence choices.

${ }^{46}$ The association between national trends in intergenerational co-residence and poverty is described by Duca (2013).
} 
estimated very small association between house price and co-residence. Though the Section IV model implies a positive association between housing cost and co-residence, this relies on a measure of housing cost that sets aside family wealth. In our application, the regional house price indices bring information both about housing costs in the region and about family wealth, conditional on the region's wages. Where high housing costs are predicted to encourage coresidence, high wealth may help families support separate residences. This prediction is reinforced empirically by our finding that co-residence is associated so closely with lower earning power. On net, the two competing forces embodied in house prices appear to generate a near-zero association between the house price index and the prevalence of intergenerational coresidence, at least in the cross section.

Finally, we estimate a positive, moderate, and insignificant association between enrollment-weighted mean tuition and co-residence for the full sample of states and years. A $\$ 1000$ increase in mean tuition is associated with a 0.14 percentage point increase in coresidence, and this estimate has a t-statistic of less than one. In the full sample, college tuition does not appear to be a strong determinant of co-residence for young consumers.

The parameters arising from year controls show the surprising strength of the time dependence of co-residence with parents. The coefficients on our set of year effects reveal a steep time path, even when conditioning on state labor and housing market conditions. The 2015 observations, for example, average 21 percentage points more co-residence than the 2003-2004 observations, all else equal.

Given a mean of 34.1 and standard deviation of 13.3 for our measure of the rate of college graduation by age 24 among the sample state-cohort cells, our data signal substantial variation in the relevance of college tuition across state-cohort populations. Therefore we are also interested in differences in the relationship between the cost of college and later coresidence with parents for regions with more and fewer college-going youth. To investigate regional heterogeneity by educational attainment, we divide the sample of states into an upper and a lower half, and eventually quartiles, based on the share of current 24-year-olds with associate's or bachelor's degrees. Our choice of graduation rate as the educational criterion used to group the states arose in part from the stability of graduation rates over the sample period. While college enrollment rates for students of traditional college ages rose meaningfully between 
2003 and 2015, the age-24 graduation rates we derive from IPEDS and Census measures are approximately flat and close to a third throughout the period. ${ }^{47}$

Dividing the sample by college graduation rate reveals distinct patterns in higher- and lower-graduation states. Columns (2) and (3) report estimates for the lower and the upper halves of states in terms of age- 24 graduation rate. For lower graduation rate states, we see a small and insignificant negative association between state-cohort tuition and the age 23 and 25 rate of coresidence with parents. The higher graduation rate states, however, behave differently. There we see a positive and significant association between state-cohort tuition and co-residence, with a state-cohort facing a $\$ 1000$ higher mean tuition level realizing a 0.72 percentage point higher rate of co-residence by ages 23 and 25, on average. Given a rise in mean tuition from 2003 to 2015 of roughly $\$ 6202$ for this group, the estimate implies that tuition may explain as much as 4.5 percentage points of the roughly 10.5 percentage point rise in co-residence observed for high graduation states over this period. The fact that the association between co-residence and tuition appears specifically for highly educated states suggests that this relationship may be driven by college costs themselves, and not by some additional local factor shaping both college budgets and subsequent youth residence choices.

The co-residence pattern is quite different for lower education states. In addition to no clear association between tuition and co-residence, in states with graduation rates in the bottom half of the distribution, we see a meaningful association between employment and co-residence. While the estimated association between the state-year's QCEW employment to population ratio and intergenerational co-residence is negative and insignificant for both the pooled sample and the higher graduation states, the lower graduations states show a positive, large, and highly significant relationship between employment and co-residence. Among lower education states, a one percentage point higher employed share of the population is associated with a 0.16 percentage point higher rate of co-residence with parents at ages 23 and 25. This coefficient is significant at the one percent level. ${ }^{48}$

\footnotetext{
${ }^{47}$ Hence our heterogeneity analysis is insensitive to dividing states according to the graduation rate of current 24year-olds or of 24-year-olds from a fixed, pre-sample year. Note that the climbing enrollments and relatively stagnant graduation rates we observe are symptomatic of a concern shared by higher education researchers. See, for example, Athreya and Eberly (2013) and Looney and Yannelis (2015).

${ }^{48}$ This association is consistent with positive social interaction effects with employed parents who may be better able to help their children with residence, finding jobs, and other needs.
} 
In sum, while intergenerational co-residence for higher education states is closely tied to college costs, for lower education states we see co-residence instead associated meaningfully with state employment. This pattern persists in finer graduation rate categories: when we estimate in quartiles of state graduation rates, reported in columns (4) through (7), we find a negative, insignificant coefficient on tuition for the lowest quartile, followed by positive and economically meaningful coefficients on tuition for the upper three quartiles, with the largest coefficient appearing for the highest graduation rate quartile. Here we find a $\$ 1000$ increase in mean tuition associated with a 0.94 percentage point increase in co-residence, and this estimate is significant at the five percent level. Turning to employment, however, we find a positive association between employment and co-residence for the lower two quartiles of states in terms of graduation rates, with a significant coefficient of 0.327 on employment for the second quartile indicating a 0.327 percentage point increase in co-residence associated with one percentage point more employment there. And yet, in the fourth quartile, we see a negative and marginally significant coefficient on employment. Our heterogeneity analysis reveals distinct co-residence reactions to college costs and employment conditions for more and less educated regions.

Turning to the fixed effect coefficients, this division of the sample into higher and lower education regions also reveals interesting differences in the time pattern of intergenerational coresidence. While the year dummy coefficients climb from 4.506 in 2005 to 27.965 for the first quartile of states by graduation rate, they reach only 1.449 by 2005 and 9.487 by 2015 for the fourth graduation rate quartile. ${ }^{49} \mathrm{By}$ and large, we see a substantially steeper upward trend in coresidence for lower education states, and one closely associated with job market conditions. At the same time, we see a lesser but still quite substantial upward trend in co-residence for higher education states, and one more closely associated with the cost of college.

\section{b. Stock model estimates of other residence choices}

Given the steady climb in intergenerational co-residence that we have measured and estimated above, what residential arrangements are younger Americans now forsaking, and why? Next we estimate empirical specifications equivalent to those described by expression (1), but we replace the outcome of the share of youth co-residing with parents with three alternative residential

\footnotetext{
${ }^{49}$ Each of the first quartile coefficients is significant at the one percent level. The fourth quartile coefficients are significant at the ten and five percent levels, respectively.
} 
arrangements. The additional arrangements we model are the share of youth living with groups of roommates, in couples, and the share living alone. These four categories - living with parents, with groups of similarly-aged roommates, in a couple, or alone - are defined to be exhaustive. Each observation in our sample can be categorized as one of the four. The measurement of each living arrangement follows the definitions laid out in Section III on youth residence trends. We report estimates of our models of other living arrangements in Table 3.

As intergenerational co-residence rates ascend from 2003 to 2015, the estimated year effects in Table 3 reveal an offsetting decline in the rate of living with roommates. This is particularly true for lower education states. The rate of living in couples is estimated to be comparatively flat, though this masks a steep increase for lower-education states. Finally, in the pooled sample and in high and low graduation groups, we observe a modest decline in the rate of living alone.

Turning to college costs, the higher education states that showed a large positive association between tuition and intergenerational co-residence also show an approximately offsetting decline in living with groups of roommates as tuition rises. A $\$ 1000$ increase in tuition is associated with a 0.72 percentage point decline in co-residence with parents and a 0.86 percentage point decline in living with roommates. ${ }^{50}$ This same group shows little association between tuition and living either in couples or alone. Our evidence suggests that young Americans living in higher education states responded to the tuition increases that characterized the 2003-2015 era by increasingly living with parents at the cost of living independently with roommates.

The picture for lower education states appears to be quite different. Though these states have lower graduation rates, college enrollment is quite common in all states, and we expect substantial exposure to college costs for both groups. In the lower education states, our estimates indicate no significant or substantial response to tuition in the rates of living with parents, with roommates, or alone, but we do find a negative association between tuition and living in couples. Specifically, $\$ 1000$ increase in tuition is associated with a 0.28 percentage point decrease in the rate of living in couples.

The employment effects on other residential arrangements that we estimate are mixed and, for the most part, small. Wages show little effect on residential arrangements, aside from a

\footnotetext{
${ }^{50}$ This coefficient is significant at the five percent level.
} 
large positive association with living with roommates, particularly for lower education areas. House prices show a modest positive and significant association with living in a couple; a one standard deviation increase in the state-year house price index is associated with a 0.45 percentage point increase in coupledom, and this is true for both high and low education states.

\section{c. Geographic heterogeneity in the response to tuition}

One finds extensive variation across the United States in both population density and the prevalence of intergenerational co-residence, whether in 2003 or 2015. Further, these correlate with graduation rates. For example, the western states feature both lower graduation rates and lower rates of intergenerational co-residence. It is useful, therefore, to examine the geographic sources of our estimated tuition-co-residence relationship. ${ }^{51}$

First, we estimate our baseline model, as described by expression (1) and reported in Table 2, interacting the tuition regressor with indicators for each of the four U.S. Census regions. Though sample size begins to limit the precision of the estimates in finer categories, we also perform this exercise separately for higher and lower graduation rate states. Table 4 reports the estimates with region-specific tuition estimates for the full sample and top and bottom halves of the graduation rate distribution. In the pooled data, we estimate no significant or sizable tuition effects on co-residence in any of the four Census regions. Separating the tuition effect across the four Census regions demonstrates that the tuition association with intergenerational co-residence that we observe for the higher graduation rate sample arises from a positive relationship in the Northeast and Midwest, and, to a degree, in the South Atlantic. (The precision of some of these estimates, however, is reduced by the smaller sample sizes of the graduation rate by Census region subcategories.) In particular, we observe a coefficient indicating that a $\$ 1000$ increase in tuition is associated with a 0.66 percentage point increase in intergenerational co-residence in the Northeast. ${ }^{52}$

However, the relationship of co-residence to tuition appears to be quite different in the West. In the West for both the low and high graduation rate states we estimate a negative, and in one case substantial (though statistically insignificant), association between tuition and intergenerational co-residence.

${ }^{51}$ We thank a referee and the editor for this observation.

52 This coefficient is significant at the ten percent level. 
Given the differing availability of living space in urban and rural environments, as well as the difference in educational attainment in the two, we are also interested in whether the estimated tuition-co-residence relationship arises in urban or rural locations. Table 5 reports estimates of expression (1) with the addition of a regressor representing the percent of each state living in urban areas, along with the interaction of the percent urban and the mean tuition for the state.

The estimates indicate that intergenerational co-residence is considerably less common as the population becomes more urban. (Note, of course, that the effects of time-fixed heterogeneity are absorbed by the full set of state fixed effects.) At the average tuition level for the sample, the point estimates in Table 5 column (1) indicate that a one percentage point increase in the share of the state population living in urban areas decreases intergenerational co-residence by roughly 1.16 percentage points. Further, the estimates reflect a more positive association between tuition and intergenerational co-residence in more urban states. In the pooled sample of state-years, and evaluating at the US overall percent of urban population for 2010 of 80.7 percent, the estimates indicate that a $\$ 1000$ increase in tuition is associated with a small 0.045 percentage point decline in intergenerational co-residence. However, in California, the state with the highest urban population percentage, at 95 percent, a $\$ 1000$ increase in tuition is associated with a 0.24 percentage point increase in intergenerational co-residence. This relationship arises from a positive and highly significant coefficient on the interaction between percent urban and tuition. The Table 5 estimates suggest that the positive tuition-co-residence estimate we observe elsewhere is a more urban than rural phenomenon. Moreover, the column (2) and (3) estimates reflect the now-familiar difference between the tuition-co-residence relationship in the lower and higher graduation rate states. The estimates in column (3) produce a 0.59 percentage point increase in co-residence with a $\$ 1000$ increase in tuition when evaluated at the US average percent urban of 80.7 , or a 0.74 percentage point co-residence increase with $\$ 1000$ higher mean tuition for a state with the urban percentage of California.

Overall, the evidence we have gathered on the geographic heterogeneity in the tuition-coresidence relationship reveals that the positive association between tuition and intergenerational co-residence that we find for higher education states is driven by the strength of this relationship in the Northeast and the Midwest, or, not unrelatedly, the strength of this relationship in states 
with more urban populations. The tuition-co-residence connection is much weaker, and is even estimated to be negative in some cases, in the Western states and in more rural areas.

\section{d. Flow home to parents from independent living}

Table 6 reports the coefficient estimates for the moving home model in expression (2). ${ }^{53}$ As discussed above, we move to the transition approach in order to estimate parental co-residence choices in two populations, one in which youth uniformly live on their own at the start of the two-year period, and one in which youth uniformly live with parents. In doing so, we are using the panel dimension of our data to resolve the problem of measuring location characteristics only for youth locations when sample members live independently, and only for parent locations when sample youth live with parents. This method is appealing in that it allows us to identify the effects of local conditions operating below the state level on the choice of whether to co-reside with parents. It is less effective, however, in relating college costs to co-residence, as college costs do not vary over the life-cycle, and the bulk of their variation in our IPEDS-derived measures occurs at the state level. However, to the extent that having experienced higher costs of college potentiates co-residence reactions to unobserved shocks, such as individual job loss or partnership dissolution, as might arise in the modified Kaplan model in Section IV, we may be able to capture this effect by estimating the growth model with the addition of a state-cohort tuition level.

The estimation sample consists of county-level observations of two-year changes in employment, wage, and housing price conditions, as well as the share of 23-year-olds living independently who have moved home to parents two years later. The full sample period is 20032015, with the first set of 23-year-olds observed living independently in 2003 and the last twoyear transition window closing for 25-year-olds in 2015. Columns (1), (3), and (5) reflect estimates of the model exclusively relating the growth in employment, wages, and housing costs to transitions home. Columns (2), (4), and (6) add the level of the age 20-22 enrollment-weighted state tuition mean faced by the state-cohort to what is otherwise a growth model. This latter modification is not ideal, and our preferred specification is the simple growth model. However, the reader may wonder about the role of college costs in shaping co-residence transitions. Finally, note that columns (1) and (2) include state fixed effects in the rate of transition to parents

\footnotetext{
${ }^{53}$ For the relevant scales of measurement, as well as average values of the flow variables, see Table 1.
} 
but no time dependence in co-residence changes, columns (3) and (4) add a linear time trend to this model of changes in co-residence, and columns (5) and (6) allow a full set of year-specific effects in the rate of change in co-residence, arguably an extreme approach to the specification of time dependence in a model of growth.

Estimates in Table 6 most prominently describe a protective effect of strengthening local labor markets on the independence of youth. Across all specifications, a one percentage point increase in local employment is associated with a 0.2 to 0.3 percentage point decline in the rate at which youth move home to parents over the two years. The employment share coefficient is significant at the one percent level in all cases. Increasing local wages behave similarly. A \$100 increase in average weekly wages for the county over two years is associated with a 0.12 to 0.15 percentage point decline in the rate of moving home to parents, and these estimates are also each significant at the one percent level. Strengthening local labor markets, reflected in both rising employment rates and rising wages, stabilize youth independence. ${ }^{54}$

Increasing house prices, also often associated with strengthening local economies, appear to have the opposite effect. Specifications (1) through (4) reflect a positive association between house price growth and the rate at which independent youth move home, with a one standard deviation larger growth in the house price index associated with a 1.21 to 1.92 percentage point greater rate of transition home to parents; again each coefficient estimate is significant at the one percent level. The direction and magnitude of these estimates stand to reason: as the cost of housing in the county increases, families respond with a fair amount more "doubling up". It must be noted, however, that the result is not robust to our most flexible specification of the dynamics of co-residence transitions.

Turning last to college costs, our transition model estimates uncover a positive association between the tuition faced by a state-cohort and its later rate of transition home (among those who first achieve independent living) only in the column (2) specification, which permits no time dependence in the rate of transition home between ages 23 and 25. The estimate indicates a 1.26 percentage point increase in the two-year rate of transition home for a cohort that faced $\$ 1000$ greater mean college tuition. Given the state fixed effects in this framework, the effect of statecohort tuition on transitions back to the parents' home is identified using variation between

\footnotetext{
54 These decisive results are consistent with the findings in Kaplan (2012) that the job market exerts its greatest influence on the timing of moves home.
} 
cohorts in a given state in college costs, and hence accounts for state-specific levels and linear trends in the influence of the degree of support for youth and education on the two-year transitions.

Yet adding linear or fully flexible year controls leaves a negative and insignificant tuition coefficient for the rate of moving home. Of course, the cost of college in part shapes the population living independently by age 23 , and so, recalling the Section IV modified Kaplan model, theory generates an ambiguous prediction for association between college costs and the rate of return for post-schooling youth who have achieved independence. For this and other reasons described above, the tuition coefficient is only limitedly informative.

\section{e. Flow away from parents to independent living}

Table 7 reports the coefficient estimates for the model of the rate at which dependent youth move away from home. Analogous to the Table 6 move-in estimates, the sample consists of county-level two-year changes in employment, mean wages, and house price indices. These are related to the rate at which 23-year-old county residents living with parents move out over the subsequent two years. As before, columns (1), (3), and (5) estimate using only growth regressors and columns (2), (4), and (6) add the levels of the relevant state-cohort tuition means, which precede the estimation window. And as before, columns (1) and (2) impose no time dependence beyond state fixed effects in the transition rates, columns (3) and (4) include a linear time trend in the rate of change in co-residence, and columns (5) and (6) include free yearly effects in the rate of residence changes.

By and large, the economic determinants of moving away from parents are less obvious based on the estimates than the economic determinants of moving home. We find no significant association between county employment growth and the rate of moving out. The estimates show a small, positive and in some cases marginally significant relationship between house prices and the rate at which youth move away from their parents, and yet a negative, smaller, and insignificant association once one moves to the most flexible specification of time dependence.

The wage coefficients, however, are decisive. A \$100 increase in the county's mean weekly wage over two years is associated with approximately a 0.4 percentage point decline in the rate at which county youth move away from their parents. ${ }^{55}$ Weighing the wage coefficients for both

\footnotetext{
55 The wage coefficient is significant at the one percent level in all cases.
} 
the move in and the move out, it appears both that local wage growth in the youth location stabilizes youth independence and that local wage growth in the parent location stabilizes coresidence with parents.

As in the model of transitions home, transitions away are closely associated with higher state-cohort college costs only where the model omits a time trend in co-residence transitions. In column (2), we estimate a 1.5 percentage point decline in the rate of transitions away from parents in response to a $\$ 1000$ greater state-cohort college tuition level. However, adding either a linear or fully flexible time dependence of the rate of residence changes leaves a smaller positive and insignificant tuition coefficient. As with the rate of moving home, the population of youth co-residing with parents by the age of 23 is shaped in part by college costs, and college costs affect a cohort of youth at one point over the life-cycle. As a result, the predictions of our Section IV model for the direction of the association between past tuition and subsequent co-residence transitions are ambiguous. Moreover, it is not clear that our approach could be expected to have enough identifying power under such an extremely flexible model of time effects on intergenerational co-residence to estimate this direction informatively.

\section{Discussion and Conclusions}

This paper investigates young people's parental co-residence rates in the CCP, and the relationship among co-residence decisions and local house prices, local employment conditions, and the cost of college. Evidence from the CCP shows that co-residence with parents has been persistently increasing for 25-year-olds since 2004, while the number of 25-year-olds living with more than one roommate has declined steadily. The co-residence trend corroborates similar findings using the Census, CPS and CCP in Matsudaira (2016), Paciorek (2014), and Dettling and Hsu (2014). Simultaneously, homeownership has decreased for both age groups, and college tuitions have continued to grow.

In a pooled sample of state-cohort-year cells measuring the mean rate of co-residence with parents among youth at ages 23 and 25, we find that co-residence arises most in the presence of low or declining wages. Accounting for time-fixed heterogeneity in intergenerational co-residence across states, as well as freely varying yearly shifts in overall co-residence, we find that when states face average weekly wages that are $\$ 100$ lower, their rate of intergenerational 
co-residence is, on average, 2.2 percentage points greater. High rates of living with parents appear to be associated with periods of weaker earnings in the region.

By splitting our sample of state-cohort-year cells into those characterized by higher and lower college graduation rates, we uncover some interesting distinctions between the recent growth in intergenerational co-residence for states whose populations have higher and lower educational attainment. Among states with more educated populations, youth cohorts' rates of co-residence with parents following schooling are particularly responsive to changes in the college tuition that students confronted when they were of college age. Presumably this is also, in part, as a greater share the population is affected by higher tuition. Among the more highly educated half of states, a $\$ 1000$ increase in the tuition facing a state-cohort is associated with a 0.72 percentage point higher rate of co-residence with parents. The analogous co-residence increase for the top quartile of states, in terms of graduation rate, is 0.94 percentage points. Hence for the higher graduation rate half of states, the observed $\$ 6202$ tuition climb over the period is able to account for 4.5 of the observed 10.5 percentage point rise in co-residence with parents. The influences on intergenerational co-residence of more conventional economic factors, such as jobs and housing, for the more highly educated states are estimated to be comparatively modest.

Among lower graduation rate states, the picture is quite different. We find no clear response of co-residence with parents to college tuition movements from cohort to cohort, and decisive evidence of a response to job market conditions. States with lower educational attainment, then, make co-residence choices that appear to be closer to the jobs-based model of residential independence of Kaplan (2012), for example. For the lower graduation rate states, we estimate a 3.9 percentage point greater rate of co-residence with parents, on average, in times when mean weekly wages in the state are $\$ 100$ lower. In addition, the residual year effects in our tuition model, after controlling for time-varying state economic conditions and time-fixed state factors, increase far more steeply from 2003 to 2015 for the half of states with lower educational attainment. While our estimates indicate a 13 percentage point secular increase in intergenerational co-residence for the high graduation rate half of states (controlling for economic conditions and college costs), the analogous increase for the lower graduation rate half of states is 25 percentage points. 
Analysis of the geographic heterogeneity in tuition effects on co-residence reveals that the tuition and co-residence association we observe for the higher college graduation rate states arises primarily in the Northeast and Midwest, or, relatedly, among states with a higher percentage of population living in urban areas. All estimates in the paper point in the direction of a tighter positive association between tuition and co-residence in regions of the U.S. where youth are more likely to enroll in, or graduate from, college. In addition, while the states of the West have also experienced a pronounced secular climb in intergenerational co-residence, the description of a young worker lingering longer with parents in response to a large positive shock in the cost of college turns out to be a particularly poor fit for the intergenerational co-residence patterns that we observe in the West.

Estimates of other residential choices demonstrate that the move home to parents in response to climbing tuition among youth in higher graduation rate states comes at the expense of living with roommates, and not at the expense of coupledom. On the other hand, we observe a significant and fairly substantial negative association between tuition and later residence in couples for lower graduation rate states. Further, the rate at which area youth choose to live alone is estimated to be surprisingly unresponsive to college costs, jobs, or housing markets.

Transition models allow us to relate developments in local economic conditions below the state level to the decisions of young consumers to live with parents or independently. Our estimates provide decisive evidence for the role of strengthening labor markets, in terms of both wage growth and increasing employment rates, in reinforcing the independence of youth. Young consumers living independently in improving local labor markets are substantially less likely to move home. The protective effect of improving local labor markets may be weakened somewhat by strengthening local housing markets, as rising house prices are estimated to increase the rate at which youth move home to parents. ${ }^{56}$ Economic explanations for the rate at which youth move away from parents between ages 23 and 25, however, find considerably less traction. Our only clear insight regarding the economic determinants of the move out is that increasing local wages stabilize living arrangements of both kinds, with fewer youth moving away when wages increase in parent locations, and fewer youth moving home when wages increase in youth locations.

\footnotetext{
56 This latter result, however, is sensitive to specifications allowing extremely flexible time patterns in the rate of residence changes.
} 
To paint with a broad brush, our estimates of the relationship among intergenerational coresidence choices and the economic conditions under which they are made describe two distinct regional circumstances. In the first, many young students are exposed to college costs, and jumps in the tuition facing a college cohort are met with extended periods of co-residence with parents, or more moving "home" in early adulthood. In the second, fewer students confront college tuition, and local job market conditions, with particular emphasis on wages, are paramount in shaping the decision whether to live with parents or independently. Both types of regions, nevertheless, are characterized by a steep secular climb between 2003 and 2015 in the rate of intergenerational co-residence, one that operates over and above any pressure to co-reside arising from weakening local labor markets or rising costs of housing and college.

Finally, it is important to qualify our estimates relating local tuition to population averages of youth residential outcomes. Cross-sectional and transition estimates of parental coresidence patterns that rely on local aggregates may be useful in addressing the specific estimation challenges described by this paper, including both the confounding link between the measurement of local conditions and whether youth have chosen to live with parents, and any underlying heterogeneity in individual youth ability and family generosity. However, working with aggregates implies that all statements made based on the estimates reported in this paper describe local average levels and changes in the tuition cost of a degree. Higher education investments, and their returns, may be quite heterogeneous, as described by Avery and Turner (2012). While these results represent the association between the average cost of higher education in a location and the rate of remaining or returning home, they may, for example, reflect a mix of strong homeward pressure in response to low-return educational investments and a pressure toward independence in response to high-return investments. 


\section{References}

Agarwal, S., L. Hu, \& X. Huang. 2013. Rushing into American Dream? House Prices, Timing of Homeownership, and Adjustment of Consumer Credit. Federal Reserve Bank of Chicago Working Paper 2013-13.

Athreya, Kartik and Janice Eberly. 2013. "The supply of college-educated workers: the roles of college premia, college costs, and risk," Federal Reserve Bank of Richmond working paper, http://www.richmondfed.org/publications/research/working_papers/2013/pdf/wp13-02.pdf.

Autor, D., D. Dorn, and G. Hanson. 2013. The China Syndrome: Local Labor Market Effects of Import Competition in the United States. American Economic Review 103(6): 2121-2168.

Avery, R., P. Calem, \& G. Canner. 2003. An Overview of Consumer Data and Credit Reporting. Federal Reserve Bulletin 01/2003.

Avery, C. and S. Turner. 2012. Student Loans: Do College Students Borrow Too Much--Or Not Enough? Journal of Economic Perspectives, 26(1): 165-92.

Barr, A. and S. Turner. 2015. Out of Work nad Into School: Labor Market Policies and College Enrollment During the Great Recession. Journal of Public Economics 124: 63-73.

Becker, S.O., S. Bentolila, A. Fernandes, \& A. Ichino. 2010. Youth emancipation and perceived job insecurity of parents and children. Journal of Population Economics 23: 1175-1199.

Bleemer, Z., M. Brown, D. Lee, K. Strair, \& W. van der Klaauw. Echoes of Rising Tuition in Students' Borrowing, Educational Attainment, and Homeownership in Post-Recession America. Manuscript.

Board of Governors of the Federal Reserve System. 2015. Report on the Economic Well-Being of U.S. Households in 2014.

Brown, M., J. Scholz, \& A. Seshadri. 2012. A New Test of Borrowing Constraints for Education. Review of Economic Studies 79(2): 511-538.

Brown, M. \& S. Caldwell. 2013. Young Student Loan Borrowers Retreat from Housing and Auto Markets. Federal Reserve Bank of New York Liberty Street Economics Blog.

Brown, M., S. Caldwell, \& S. Sutherland. 2014. Just Released: Young Student Loan Borrowers Remained on the Sidelines of the Housing Market in 2013. Federal Reserve Bank of New York Liberty Street Economics Blog.

Brown, M., J. Grigsby, W. van der Klaauw, J. Wen, and B. Zafar. 2014. Financial Education and the Debt Behavior of the Young. Federal Reserve Bank of New York Staff Reports 634.

Brown, M., A. Haughwout, D. Lee, J. Scally, \& W. van der Klaauw. 2015a. The Student Loan Landscape. Federal Reserve Bank of New York Liberty Street Economics Blog. 
Brown, M., A. Haughwout, D. Lee, \& W. van der Klaauw. 2015b. Do We Know What We Owe? A Comparison of Borrower- and Lender-Reported Consumer Debt. Federal Reserve Bank of New York Economic Policy Review.

Card, D. \& T. Lemieux. 2000. Adapting to Circumstances: The Evolution of Work, School, and Living Arrangements among North American Youth. In Youth Employment and Joblessness in Advanced Countries, ed. Blanchflower and Freeman. Chicago: University of Chicago Press.

Cooper, D. \& J.C. Wang. 2014. Student Loan Debt and Economic Outcomes. Federal Reserve Bank of Boston Current Policy Perspectives 14-7.

Consumer Financial Protection Bureau (CFPB). 2013. Student Loan Affordability: Analysis of Public Input on Impact and Solutions. Washington, DC.

Dettling, L. \& J. Hsu. 2014. Returning to the Nest: Debt and Parental Co-Residence Among Young Adults. Federal Reserve Board Finance and Economics Discussion Series 2014-80.

Dettling, L. \& J. Hsu. 2015. Why Boomerang? Debt, Access to Credit, and Parental Co-residence among Young Adults. FEDS Notes, https://www.federalreserve.gov/econresdata/notes/feds-notes/2015/whyboomerang-debt-access-to-credit-and-parental-co-residence-among-young-adults-20151001.html

Duca, J. 2014. When will the Kids Ever Move Out? Manuscript.

Dustmann, Christian. 2003. Return migration and the optimal migration duration. European Economic Review 47, 353-67.

Dyrda, S., G. Kaplan, \& J. Ríos-Rull. 2012. Business Cycles and Household Formation: The Micro vs the Macro Labor Elasticity. NBER Working Paper 17880.

Ermisch, J. 1999. Prices, Parents, and Young People's Household Formation. Journal of Urban Economics 45: 47-71.

Federal Reserve Bank of New York (FRBNY). 2014. Quarterly Report on Household Debt and Credit, February 2014. New York.

Gicheva, D. \& J. Thompson. 2014. The Effects of Student Loans on Long-Term Household Financial Stability. University of North Carolina at Greensboro Department of Economics Working Papers 14-02.

Goldscheider, F. K. \& J. DaVanzo. 1985. Living Arrangements and the Transition to Adulthood. Demography 22(4): 545-563.

Goldscheider, F. K. \& J. DaVanzo. 1989. Pathways to Independent Living in Early Adulthood: Marriage, Semiautonomy, and Premarital Residential Independence. Demography 26(4): 597-614.

Haurin, D., P. H. Hendershott, \& D. Kim. 1993. The Impact of Real Rents and Wages on Household Formation. The Review of Economics and Statistics 75(2): 284-293.

Hershbein, B \& K. Hollenbeck. 2014. The Distribution of College Graduate Debt, 1990 to 2008: A Decomposition Approach. Upjohn Institute Working Papers 14-204. 
Houle, J. \& L. Berger. 2014. Is Student Loan Debt Discouraging Home Buying Among Young Adults?. Association for Public Policy and Management. Manuscript.

Hunt, J. 2004. Are migrants more skilled than non-migrants? Repeat, return, and same-employer migrants. Canadian Journal of Economics/Revue canadienne d'économique, 37: 830-849.

Jacob, K., \& R. Schneider. 2006. Market Interest in Alternative Data Sources and Credit Scoring. Center for Financial Services Innovation Articles 2817.

Kaplan, Greg. 2012. Moving Back Home: Insurance Against Labor Market Risk. Journal of Political Economy 120(3).

Klasen, S. \& I. Woolard. 2008. Surviving Unemployment without State Support: Unemployment and Household Formation in South Africa. Journal of African Economies 18(1): 1-51.

Kurz, C. \& G. Li. 2015. How Does Student Loan Debt Affect Light Vehicle Purchases?. FEDS Notes, February 2, 2015.

Lautz, J. 2011, March 7. Median Age of Home Buyers: 2001-2010. National Association of Realtors Economists' Outlook Blog.

Lawrence Journal-World. 2013. Republican budget writerspropose 4 percent across-the-board cut to higher education. http://www2.ljworld.com/news/2013/mar/12/republican-budget-writers-propose-4percent-across/?print

Lee, D. \& W. van der Klaaw. 2010. An Introduction to the FRBNY Consumer Credit Panel. Federal Reserve Bank of New York Staff Reports 479.

Lochner, L. and A. Monge-Naranjo. 2012. The Nature of Credit Constraints and Human Capital. American Economic Review, 101(6): 2487-2529.

Lochner, L., T. Stinebrickner, and U. Sulemanoglu. 2013. The Importance of Financial Resources for Student Loan Repayment: Evidence from the Canada Student Loans Program. CIBC Working Paper \#2013-7, University of Western Ontario.

Looney, Adam and Constantine Yannelis. 2015. "A Crisis in Student Loans?" Brookings Institution, Washington, D.C. http:/www.brookings.edu/about/projects/bpea/papers/2015/looney-yannelis-studentloan-defaults

Mather, M. \& D. Lavery. 2010, September. In U.S., Proportion Married at Lowest Recorded Levels. Population Reference Bureau Articles.

Matsudaira, J. 2016. Economic Conditions and the Living Arrangements of Young Adults. Journal of Population Economics.

McGarry, K. \& R. Schoeni. 1995. Transfer Behavior in the Health and Retirement Study; Measurement and the Redistribution of Resources within the Family. Journal of Human Resources 30: S185-S226.

MeasureOne. 2013. The MeasureOne Private Student Loan Report 2013. San Francisco, CA: D. Arvidson, D. Feshbach, R. Parikh, \& J. Weinstein. 
Mezza, Alvaro, Kamila Sommer, and Shane Sherlund. 2014. Student Loans and Homeownership Trends. FEDS Notes, October 15, 2014.

Molloy, R., C. Smith, \& A. Wozniak. 2014. Declining Migration within the U.S.: The Role of the Labor Market. National Bureau of Economic Research Working Papers 20065.

Mykyta, L. \& S. Macartney. 2011. The effects of recession on household composition: "doubling up" and economic well-being. SEHSD Working Paper 2011-4.

National Association of Realtors (NAR). 2014, March 20. February Existing-Home Sales Remain Subdued. NAR News Releases.

National Defense Authorization Act for Fiscal Year 2013, H.R. 4310.

Population Reference Bureau, 2012, Fact Sheet: The Decline in U.S. Fertility. World Population Data Sheet 2012.

State Higher Education Executive Officers. 2013. State Higher Education Finance - FY2012. http://www.sheeo.org/sites/default/files/publications/SHEF-FY12.pdf

Stock, J. H. \& M. Yogo. 2005. Testing for Weak Instruments in Linear IV Regression. Identification and Inference for Econometric Models: Essays in Honor of Thomas Rothenberg, ed. D. W. K. Andrews \& J. H. Stock, 80-108. New York: Cambridge University Press.

Whittington, L. A. \& H. E. Peters. 1996. Economic Incentives for Financial and Residential Independence. Demography 33(1): 82-97.

Wolfers, J. 2010, October 13. How Marriage Survives. The New York Times: A25. 


\section{Appendix}

a. Comparison of our estimates of the national co-residence trend to those of prior or concurrent studies using large and (arguably) reliable surveys

Of course, others have documented this large and ongoing change in intergenerational coresidence in the U.S., either over earlier periods of time or for very recent years, in parallel to this study. Their findings using large existing surveys and other sources provide us with an

opportunity to validate our measures of intergenerational co-residence in the comparatively novel, entirely administrative Consumer Credit Panel. Matsudaira (2016) studies co-residence with parents among young adult Americans using decennial Census data from 1960 through 2000 (as well as some ACS data thereafter). Matsudaira, therefore, provides a valuable point of comparison between our year 2000 intergenerational co-residence rate for 25-year-olds and a rate calculated in the large and reliable decennial Census as a part of careful prior research. Where Matsudaira measures a 25 percent rate of co-residence with parents among 25 -year-old men, and a 21 percent rate among 25 -year-old women during 2000, we find a 29 percent rate of coresidence with parents at the end of 2000 among all 25-year-olds in the CCP. Our analysis of our co-residence criterion applied to the CPS suggests that 2 percentage points out of the 29 are likely miscategorized. The distance between the Matsudaira's 23 percent co-residence rate and our 29 percent co-residence rate may be accounted for by a combination of this miscategorization and the difference generated by our broad definition of parent or similar elder and Matsudaira's parent-only criterion.

Paciorek (2014) is particularly relevant for our purposes, as he employs CPS data, an additional, detailed, and arguably quite reliable source, and he applies a measure of co-residence with parents that is quite close to our own. His broad measure of intergenerational co-residence status for 18- to 31-year-olds in the 2000-2012 March CPS includes youth who are "living with older relatives", and excludes those living in group quarters. Hence Paciorek's co-residence criterion closely resembles an implementation of our CCP co-residence criterion for the survey data of the CPS. Using this approach, he traces an increase in intergenerational co-residence among 18- to 31-year-olds in the CPS from 39 to 46 percent between 2000 and 2012. By comparison, we measure an increase from roughly 29 percent to more than 44 percent over the same period for 25-year-olds in the CCP. This comparison demonstrates two things: the height of co-residence at the end of our panel is not evidence of anomalous measures or poor data quality, 
but instead aligns with the surprising height of intergenerational co-residence rates measured by other researchers using reliable sources. Second, we chose to study ages in the mid-twenties because, in our data, this seemed to be the age at which co-residence was changing most rapidly. Where the vast majority of 18 -year-olds co-reside with elders and thirtysomethings have largely gained independence, the residential circumstances of Americans' mid-twenties appear to be undergoing rapid reform. Hence we are unsurprised to find a flatter co-residence trend for the average among 18- to 31-year olds than the trend we measure for 25-year-olds, who stand at the precise point of the greatest residential upheaval.

Finally, Dettling and Hsu (2014, 2015) measure intergenerational co-residence in the CPS over many years, including very recent waves. This final point of comparison with the literature allows us to consider the accuracy of our CCP co-residence measure through 2013. Dettling and Hsu adopt a narrower definition of intergenerational co-residence: living with a parent, which they can measure reasonably reliably given the detail available in the CPS. ${ }^{57}$ They track co-residence for CPS youth who are ages 18 to 31. The prevalence of co-residence with parents in their data is first flat near 31 percent over the early- and mid-2000s, and then climbs from roughly 31 to 37 percent by $2013 .{ }^{58}$ Despite the narrower co-residence criterion that Dettling and Hsu apply, the rate they measure reaches a height that approaches the 43 percent that we observe in the CCP for 2013. Like the Dettling and Hsu CPS series, our CCP coresidence trend includes a comparatively flat region in the mid-2000s. An important point of distinction is the wide age 18 to 31 band used in each of the CPS papers, as compared with our age 25 trend. Like Paciorek, Dettling and Hsu's age 18 to 31 co-residence slope is considerably flatter than the slope of intergenerational co-residence among 25 -year-olds that we measure in the CCP.

\footnotetext{
${ }^{57}$ As an interesting but likely inconsequential, side note, we have been surprised to learn of the difficulty inherent in measuring co-residence with parents in both survey and administrative data. In survey data, in order to infer coresidence with parents, one must either ask about living with parents outright, which is a somewhat narrow survey item to be applied to every household member and is thus unpopular, or one must document the structure of relationships among all household members. The CPS, for example, tracks up to 15 household members. The exact relationship between each possible pair among the 15 is not covered in its entirety, as of course this would be a prohibitively costly data gathering exercise. However, the relationship accounting available in the CPS remains unusually detailed.

${ }^{58}$ Relatedly, a 2013 report from the Pew Research Center, based on their own analysis of the March Current Population Survey (CPS), reported that 32 percent of 18-31-year-olds in 2007, 34 percent in 2009, and 36 percent in 2012 live with parents. The Pew analysis defines an individual as living with a parent only if she lives with a parent or step-parent, not a parent-in-law or the partner of a parent, and only if she is not herself a head of household.
} 


\section{b. On the exogeneity of state-cohort mean tuition to post-schooling residential outcomes}

State-cohort average tuition is included in expression (1) as an exogenous measure of the cost of college for the population whose residential outcome we are estimating. The assumption we impose is that variation in this tuition measure, once we condition on the calendar year, the state, and the employment, youth unemployment, mean wages, and house price index for the state-cohort-year, is exogenous to the state-cohort-year's rate of intergenerational co-residence (or living alone, with roommates, or in a couple). Practically speaking, we are all aware of extensive time-fixed, cross-state variation in college and university tuition. Further, the broader business cycle in the U.S. can be expected to affect state budgeting, and therefore state appropriations for higher education, in a non-linear fashion over time. Local economic conditions may deviate from the national cycle, and these are accounted for in the estimation using four standard measures of prevailing economic conditions. The relationship that we estimate between college costs and residential outcomes is identified using variation in average tuition beyond the variation associated with each of these aforementioned factors.

Examples of the sort of tuition variation we have in mind often arise from legislative shocks. In one example, large portions of the higher education budgets of 43 states in 2010, and 31 states in 2011, were heavily dependent on federal American Recovery and Reinvestment Act (ARRA) funds. In 2012, federal ARRA funding dried up for the states. This constituted a meaningful negative shock to the higher education budgets of 31 states, and yet not a meaningful shock to the higher education budgets of 19 states. Any difference across states in tuition growth from 2011 to 2012 or even 2013 generated by the differential impact on states of the withdrawal of ARRA funding, over and above its effects on local labor and housing markets, will serve to identify our tuition coefficient. ${ }^{59}$ Another example appears in Lawrence Journal-World (2013). In 2012, Republican and Democratic Kansas state legislators engaged in negotiations regarding the percent of funds to cut from the state's higher education budget appropriations. To the extent that realizations of such negotiations in state legislatures from year to year deviate from the state's usual budgeting outcomes, from national trends in states' higher education budgeting, and from regional business cycles as represented by state employment, youth unemployment, wages,

\footnotetext{
${ }^{59}$ On state appropriations, state board of regents tuition-setting, and the process described in this paragraph, see, for example, State Higher Education Executive Officers (2013).
} 
and house prices, they will contribute to the identification of the tuition association with youth residence outcomes that we estimate.

Other researchers have turned to state-year tuition means for arguably exogenous variation in the cost of college. Kane (1994), Rouse (1995), and Souleles (2000), for example, have relied on state college tuition averages to estimate, respectively, the influence of college costs on the enrollment rates of African American students, the influence of community colleges on final educational attainment, and the influence of college costs on the consumption and saving decisions of students' families.

Several empirical findings argue for the validity of the exogeneity assumption for our college cost proxy. In Bleemer et al. (2017), we find that estimates of the tuition effect on educational attainment, student borrowing, and homeownership are insensitive to the inclusion (or exclusion) of controls for local employment, youth unemployment, wages, and house prices. These results go some distance toward addressing the possibility of endogeneity of state-cohort tuition shocks to youth residential outcomes via local economic conditions. Further, we estimate precise and inconsequential associations of educational attainment (college enrollment, college graduation, years of schooling) with state-cohort tuition levels. These results call into question any claims that the tuition association with residential outcomes that we estimate arises solely from schooling attainments that decline as tuition rises. (Though, if present, we would interpret such schooling effects as simply one mechanism by which college costs affect young Americans' post-college outcomes.)

Of course, tuition and residential outcomes could both be driven by aspects of local economic conditions not represented in employment, youth unemployment, wage, and house price measures. However, if this were the case, we might expect such factors to affect coresidence outcomes for youth who do and do not attend college. The results in section VI, however, indicate a substantial and precisely estimated tuition-co-residence relationship only among higher college graduation states. ${ }^{60}$ Much stronger estimated tuition effects for populations

\footnotetext{
${ }^{60}$ The notion that youth in higher education states should be more responsive to within-state tuition changes in their post-schooling living arrangements is akin to the assumption underlying U.S.-China trade shock studies of the U.S. labor market. There, the effect of manufacturing trade with China on U.S. workers is expected to be greater in regions in which workers participate more heavily in the affected sector. See, for example, Autor, Dorn, and Hanson (2013).
} 
more exposed to college tuition would seem to argue against broader local economic factors that drive both tuition and co-residence. ${ }^{61}$

In related research, Mezza et al. (2016) instrument student debt using state-cohort mean tuition and demonstrate that their estimated effect is unresponsive to the inclusion (or exclusion) of measures of local economic conditions. Further, they find that homeownership is closely associated with state-cohort mean tuition only for youth who attend college, and unrelated with tuition among youth who do not attend college.

${ }^{61}$ Of course, our local aggregates must each include some college-educated youth, and so a finding of some tuition effect on residential outcomes among lower education regions would not necessarily signal endogeneity of tuition to residential outcomes via unmeasured local conditions. 
Figure 1: Enrollment-weighted mean public and private tuition by state, 2001-2013

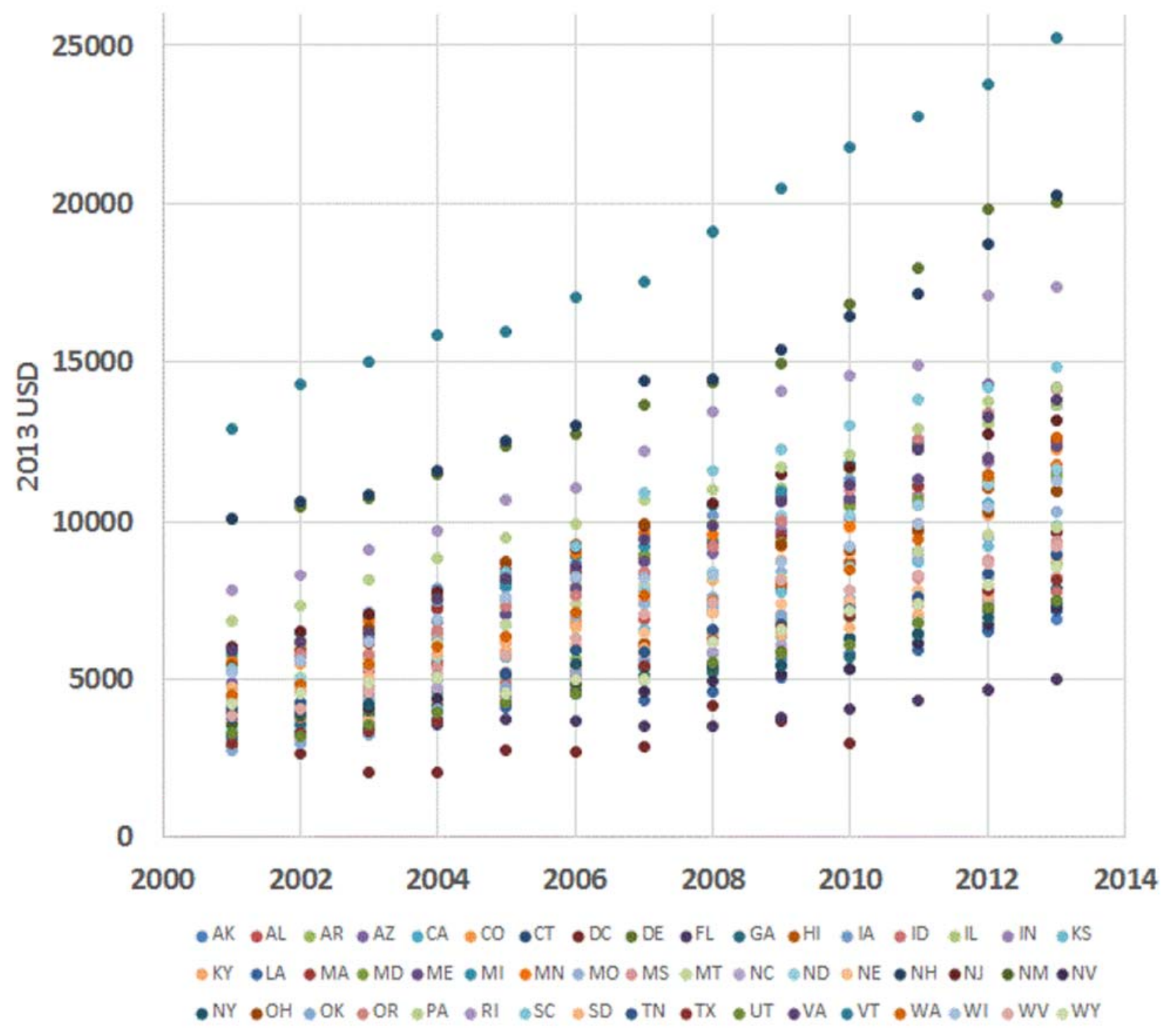


Figure 2: Co-residence with parents among 25-year-olds in the CCP, 19992016

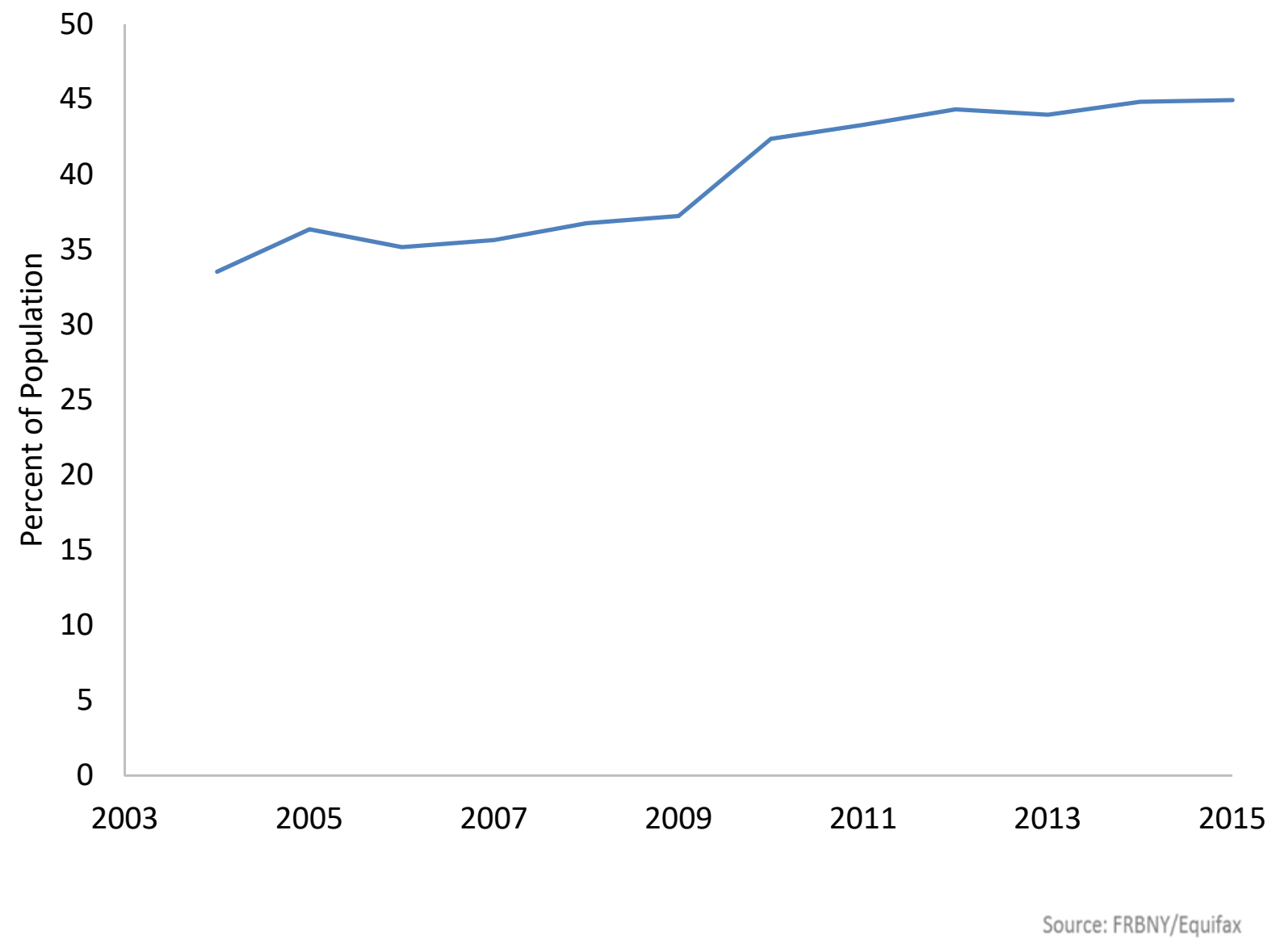


Figure 3a: Percentage of 25-year-olds living with parents in 2002-2003

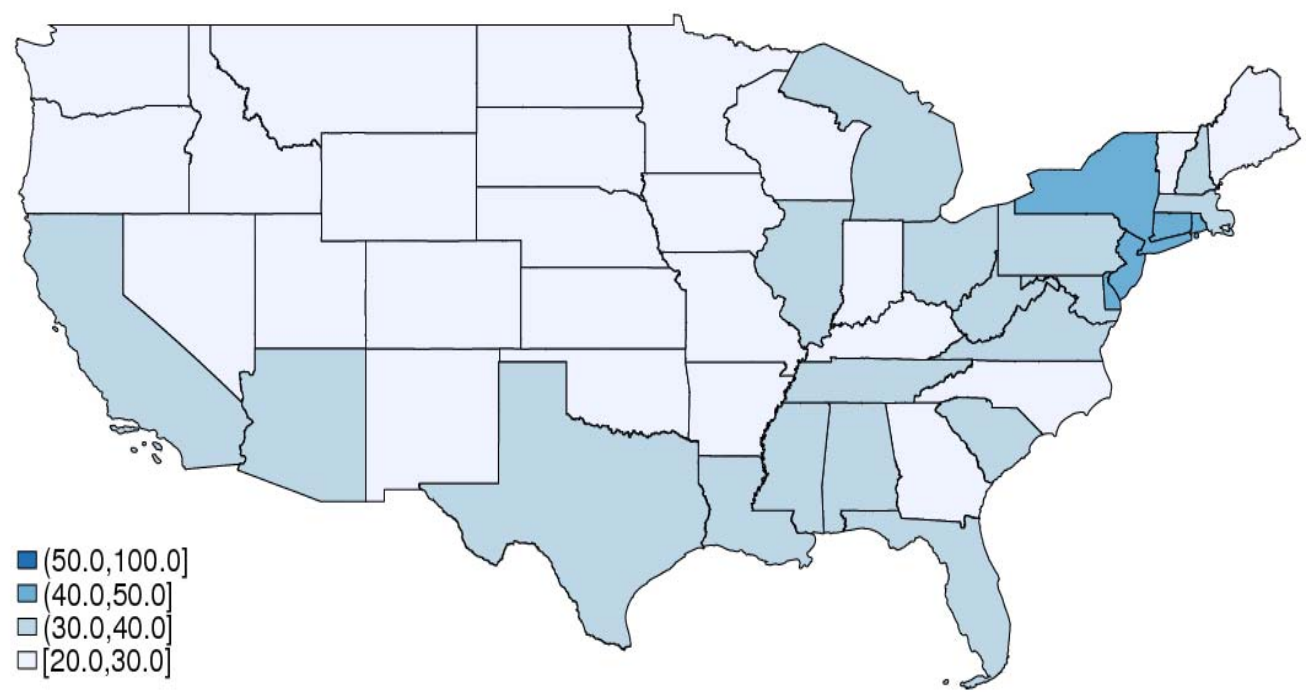

Figure 3b: Percentage of 25-year-olds living with parents in 2012-2013

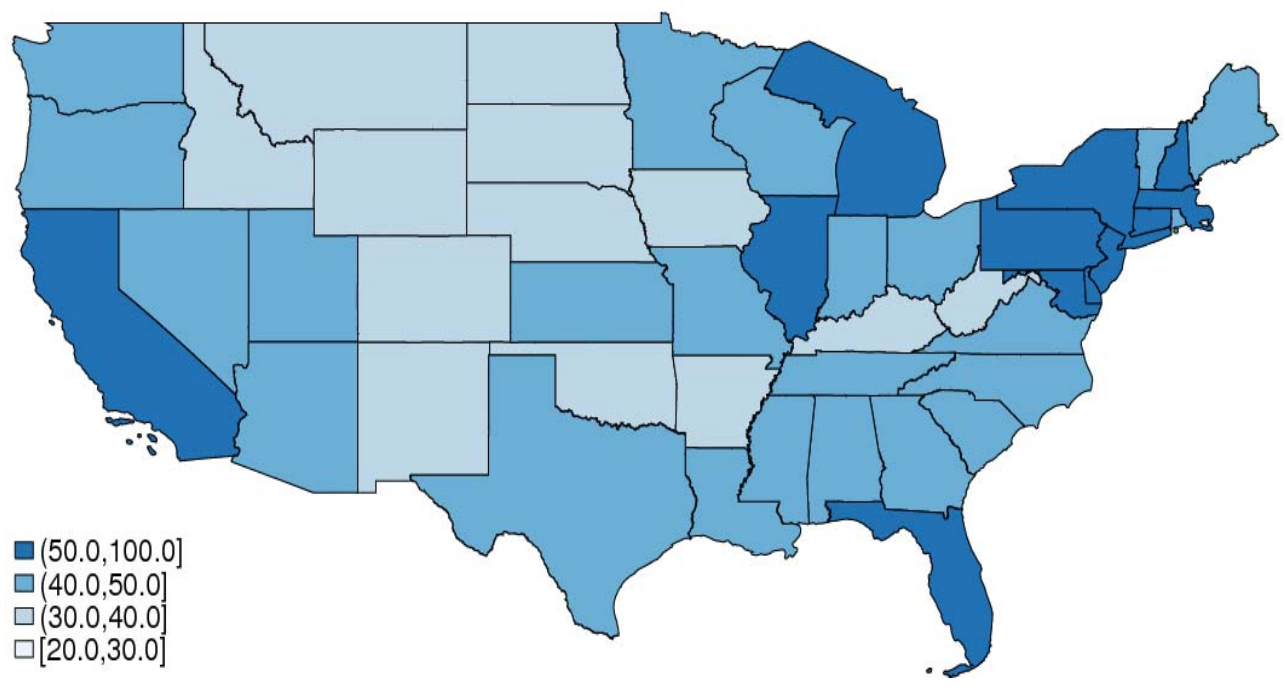


Figure 4: Changes in Student Debt and Parental Co-Residence, 2008 to 2013

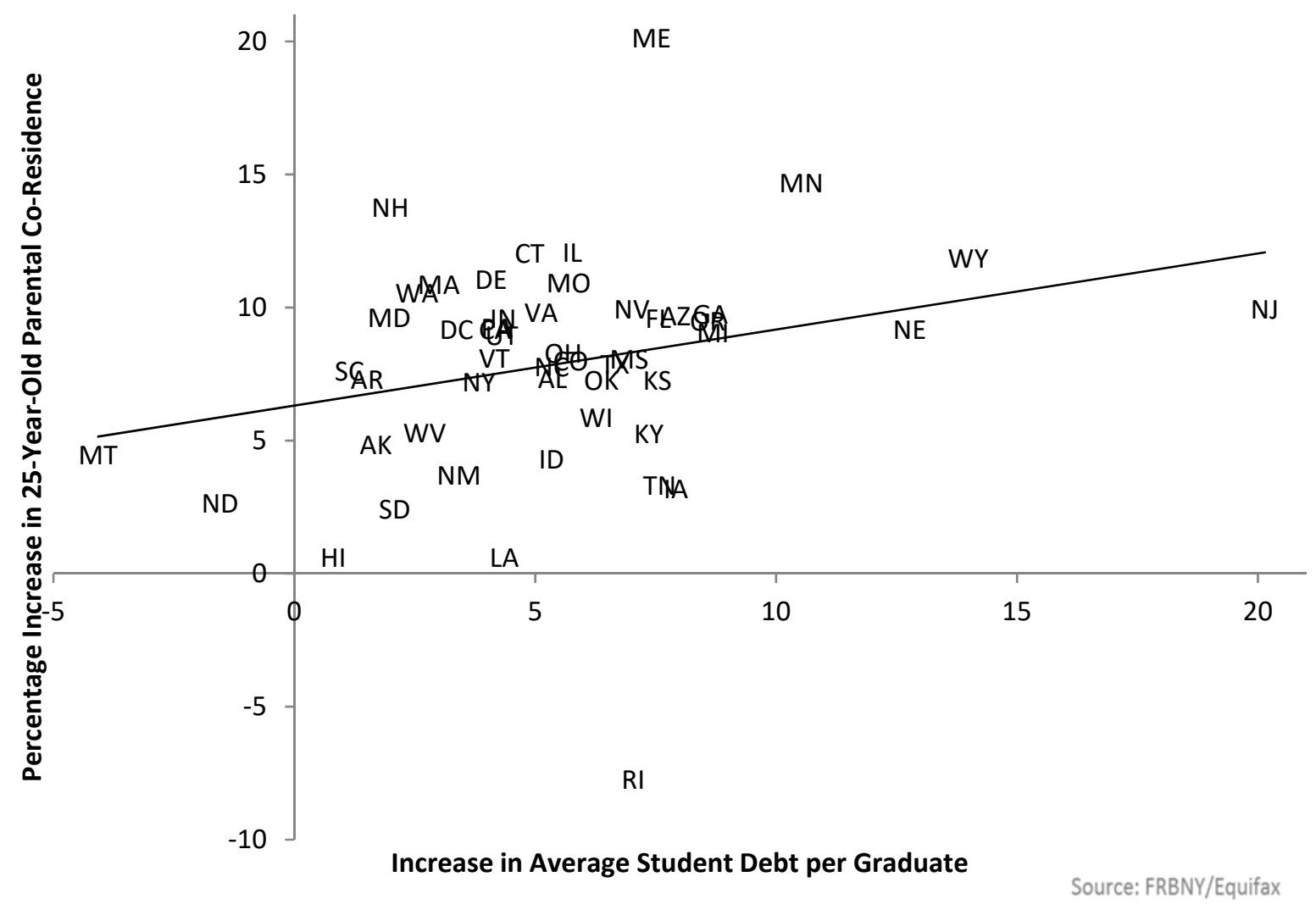


Figure 5: Residential arrangements of 25-year-olds in the CCP, 1999-2016

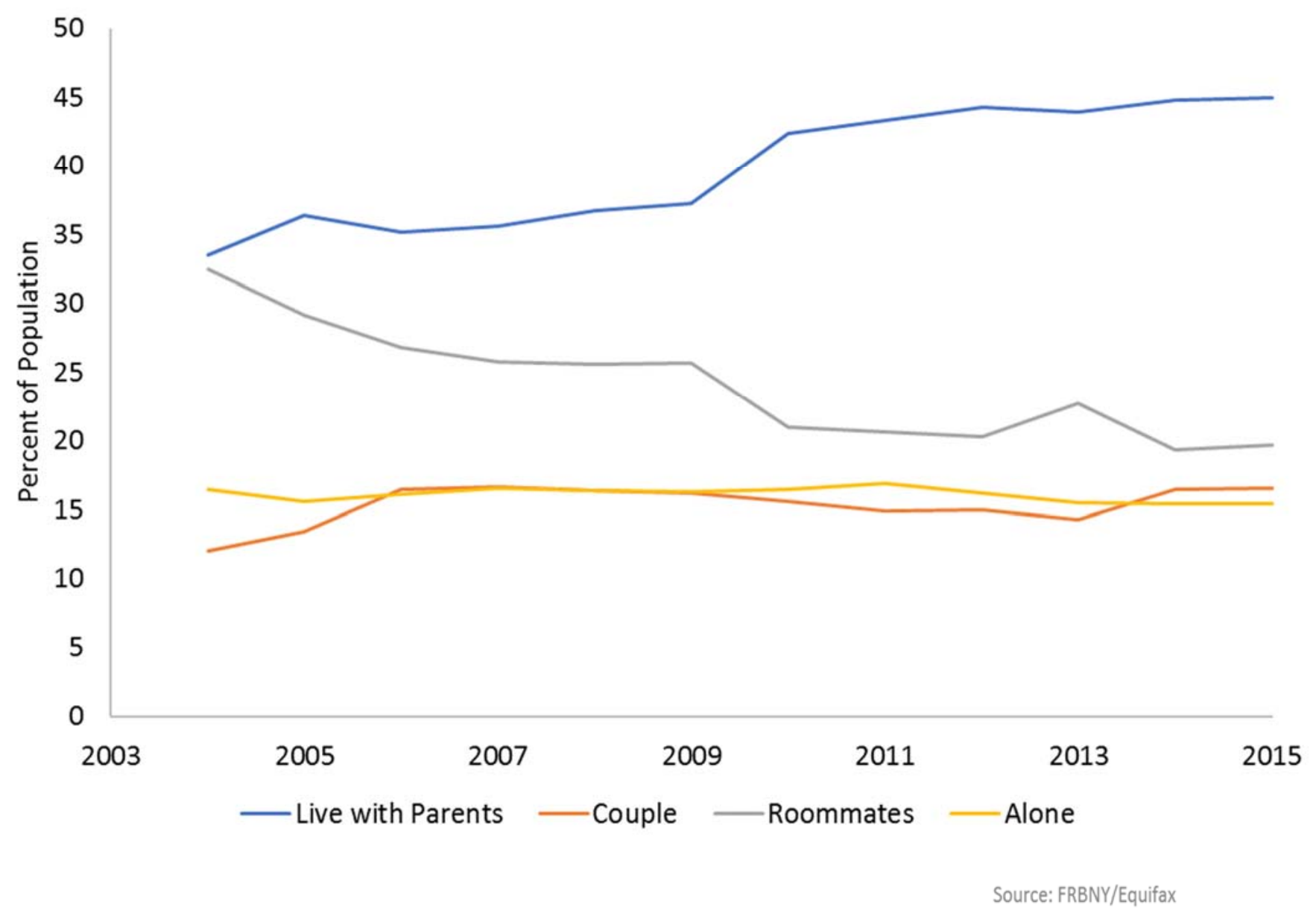


Table 1: Descriptive statistics, pooled locations and parent v. independent youth locations

\begin{tabular}{|c|c|c|c|c|}
\hline & $(1)$ & $(2)$ & (3) & (4) \\
\hline & Stock Values & \multicolumn{3}{|c|}{ Flow Values } \\
\hline & All & All & No Parents & Parents \\
\hline \multirow[t]{2}{*}{ Employment to Population, QCEW } & 57.54 & -0.860 & 0.069 & -0.745 \\
\hline & (13.27) & $(2.6)$ & $(13.66)$ & $(9.85)$ \\
\hline \multirow[t]{2}{*}{ Youth unemployment, CPS } & 10.62 & -0.021 & 0.130 & -0.252 \\
\hline & $(3.48)$ & $(3.76)$ & $(3.82)$ & $(3.72)$ \\
\hline \multirow[t]{2}{*}{ Average Weekly Wage, \$100s, QCEW } & 8.6 & 0.201 & 0.247 & 0.134 \\
\hline & $(1.7)$ & $(1.69)$ & $(1.89)$ & $(1.36)$ \\
\hline \multirow[t]{2}{*}{ House Price Index, 100 in 2000, CoreLogic } & 149.76 & 3.359 & 2.803 & 3.720 \\
\hline & (33.79) & $(30.27)$ & (30.88) & $(28.78)$ \\
\hline \multirow[t]{2}{*}{ State-level urban pct of population, Census } & 74.1 & - & - & - \\
\hline & $(14.7)$ & & & \\
\hline Graduation rate, state-cohort, IPEDS & 34.1 & 28.90 & 29.37 & 29.26 \\
\hline (levels in all columns) & $(13.3)$ & $(10.81)$ & $(10.81)$ & $(10.86)$ \\
\hline \multirow{2}{*}{$\begin{array}{r}\text { Average Total Sticker Cost, } \$ 1000 \text { s, IPEDS } \\
\text { (levels in all columns) }\end{array}$} & 11.8 & 12.47 & 12.02 & 12.99 \\
\hline & (4.7) & $(4.41)$ & $(4.27)$ & $(4.50)$ \\
\hline \multirow[t]{2}{*}{ Living with Parents, CCP } & 39.8 & 41.85 & - & - \\
\hline & $(9.2)$ & $(49.33)$ & & \\
\hline \multirow[t]{2}{*}{ Move in / out over two years, CCP } & - & - & 18.23 & 33.73 \\
\hline & & & $(25.43)$ & (33.46) \\
\hline$N=$ & 1,020 & 546,824 & 273,574 & 196,864 \\
\hline
\end{tabular}

Notes: Column (1) data are state-year-cohort aggregates. Column (2) - (4) data are county-yearcohort aggregates. Standard deviations in parentheses. Tuitions are state-cohort averages of age 20-22 tuition for each cohort. 
Table 2: Fixed effects model of the share of 23 and 25 year-olds in the state who are living with parents

\begin{tabular}{|c|c|c|c|c|c|c|c|}
\hline & (1) & (2) & (3) & (4) & (5) & (6) & (7) \\
\hline & All & Lower half grad rate & Upper half grad rate & First quartile & Second quartile & Third quartile & Fourth quartile \\
\hline \multirow[t]{2}{*}{ Tuition mean, \$1000s, IPEDS } & 0.140 & -0.051 & $0.718 * *$ & -0.217 & 0.696 & 0.652 & $0.935 * *$ \\
\hline & (0.198) & $(0.229)$ & $(0.265)$ & $(0.341)$ & $(0.413)$ & $(0.781)$ & $(0.380)$ \\
\hline \multirow[t]{2}{*}{ Employment to Population, QCEW } & -0.034 & $0.160 * * *$ & -0.072 & 0.108 & $0.327^{* * *}$ & 0.046 & $-0.146 *$ \\
\hline & $(0.062)$ & $(0.049)$ & $(0.067)$ & $(0.185)$ & $(0.080)$ & $(0.132)$ & $(0.082)$ \\
\hline \multirow[t]{2}{*}{ Youth unemployment, state, CPS } & 0.060 & 0.065 & 0.053 & 0.110 & 0.020 & -0.013 & 0.073 \\
\hline & $(0.062)$ & $(0.072)$ & $(0.079)$ & $(0.144)$ & $(0.069)$ & $(0.109)$ & $(0.075)$ \\
\hline \multirow[t]{2}{*}{ Avg. Weekly Wage, \$100s, QCEW } & $-2.119 * * *$ & $-3.884 * *$ & -1.577 & $-5.689 *$ & -2.886 & -1.588 & -1.616 \\
\hline & (0.709) & $(1.669)$ & (0.940) & $(2.942)$ & $(2.823)$ & (2.157) & (1.077) \\
\hline \multirow{4}{*}{$\begin{array}{r}\text { House Price Index, } 100 \text { in 2000, } \\
\text { CoreLogic } \\
\text { Age }=23\end{array}$} & $-0.013^{*}$ & -0.005 & -0.012 & 0.014 & -0.007 & -0.022 & -0.005 \\
\hline & $(0.007)$ & $(0.010)$ & $(0.026)$ & $(0.019)$ & $(0.022)$ & $(0.040)$ & $(0.026)$ \\
\hline & $6.768 * * *$ & $6.272 * * *$ & $6.946 * * *$ & $5.705 * * *$ & $6.328 * * *$ & $6.889 * * *$ & $6.839 * * *$ \\
\hline & (0.394) & $(0.418)$ & $(0.647)$ & $(0.451)$ & $(0.862)$ & $(0.769)$ & (1.063) \\
\hline \multirow[t]{2}{*}{ Year $=2005$} & $3.671 * * *$ & $4.210 * * *$ & $2.052 * * *$ & $4.506 * * *$ & $3.268 * * *$ & $2.699 * *$ & $1.449 *$ \\
\hline & $(0.409)$ & $(0.414)$ & $(0.546)$ & $(0.699)$ & $(0.557)$ & $(1.007)$ & $(0.807)$ \\
\hline \multirow[t]{2}{*}{ Year $=2006$} & $6.224 * * *$ & $6.241 * * *$ & $4.278 * * *$ & $6.282 * * *$ & $4.618^{* * *}$ & $4.690 * * *$ & $3.840 * * *$ \\
\hline & $(0.412)$ & $(0.488)$ & $(0.834)$ & $(0.862)$ & (1.117) & (1.095) & $(0.976)$ \\
\hline \multirow[t]{2}{*}{ Year $=2007$} & $7.642 * * *$ & $8.579 * * *$ & $4.416^{* * *}$ & $8.736 * * *$ & $6.354 * * *$ & $5.871^{* *}$ & 2.641 \\
\hline & $(0.736)$ & $(0.687)$ & (1.139) & $(1.271)$ & (1.697) & (2.164) & $(1.892)$ \\
\hline \multirow[t]{2}{*}{ Year $=2008$} & $9.092 * * *$ & $10.290 * * *$ & $5.315 * * *$ & $11.431 * * *$ & $6.396 * * *$ & $5.806^{*}$ & $4.588 * * *$ \\
\hline & $(0.949)$ & $(1.233)$ & $(1.197)$ & $(2.236)$ & $(2.023)$ & $(2.817)$ & $(1.566)$ \\
\hline \multirow[t]{2}{*}{ Year $=2009$} & $8.939 * * *$ & $10.346^{* * *}$ & $4.716 * * *$ & $11.368^{* * *}$ & $6.564 * * *$ & $5.534^{*}$ & 3.186 \\
\hline & $(0.965)$ & $(1.006)$ & $(1.327)$ & $(1.821)$ & $(2.218)$ & $(2.988)$ & $(2.203)$ \\
\hline \multirow[t]{2}{*}{ Year $=2010$} & $13.453 * * *$ & $15.545^{* * *}$ & $8.933 * * *$ & $17.421 * * *$ & $10.561 * * *$ & $9.994 * * *$ & $7.459 * * *$ \\
\hline & (1.164) & $(1.443)$ & (1.429) & $(2.243)$ & $(2.830)$ & (2.995) & $(2.420)$ \\
\hline \multirow[t]{2}{*}{ Year $=2011$} & $13.803 * * *$ & $16.394 * * *$ & $8.622 * * *$ & $17.662 * * *$ & $11.624^{* * *}$ & $9.738 * * *$ & $7.323^{* *}$ \\
\hline & $(1.280)$ & (1.499) & $(1.518)$ & $(2.407)$ & $(2.953)$ & (3.341) & $(2.574)$ \\
\hline \multirow[t]{2}{*}{ Year $=2012$} & $14.903^{* * *}$ & $18.229 * * *$ & $9.045^{* * *}$ & $19.915^{* * *}$ & $12.442 * * *$ & $10.623 * *$ & $6.126 *$ \\
\hline & $(1.522)$ & $(1.842)$ & $(1.984)$ & (3.166) & (3.651) & $(4.262)$ & (3.039) \\
\hline \multirow[t]{2}{*}{ Year $=2013$} & $15.556^{* * *}$ & $19.386 * * *$ & $9.064 * * *$ & $21.823 * * *$ & $12.808 * * *$ & $10.257^{*}$ & $6.767^{* *}$ \\
\hline & $(1.716)$ & $(2.398)$ & $(2.076)$ & $(4.463)$ & (3.823) & $(5.325)$ & $(3.020)$ \\
\hline \multirow[t]{2}{*}{ Year $=2014$} & $19.930 * * *$ & $24.174 * * *$ & $12.721^{* * *}$ & $25.945^{* * *}$ & $17.864^{* * *}$ & $13.923 * *$ & $10.456^{* *}$ \\
\hline & (1.804) & $(2.213)$ & $(2.200)$ & (3.791) & (4.617) & $(5.357)$ & (3.582) \\
\hline \multirow[t]{2}{*}{ Year $=2015$} & $21.069 * * *$ & $25.714 * * *$ & $13.045^{* * *}$ & $27.965^{* * *}$ & $18.154 * * *$ & $14.752 * *$ & $9.487 * *$ \\
\hline & (2.164) & $(2.698)$ & $(2.600)$ & $(4.786)$ & $(4.885)$ & $(6.628)$ & $(3.446)$ \\
\hline State FE & Yes & Yes & Yes & Yes & Yes & Yes & Yes \\
\hline R-squared & 0.881 & 0.904 & 0.863 & 0.897 & 0.928 & 0.837 & 0.909 \\
\hline$N=$ & 1019 & 475 & 544 & 227 & 248 & 282 & 262 \\
\hline
\end{tabular}

Notes: $*, * *$, and $* * *$ indicate significance at the ten, five, and one percent level, respectively. The sample covers 2003-2015. 


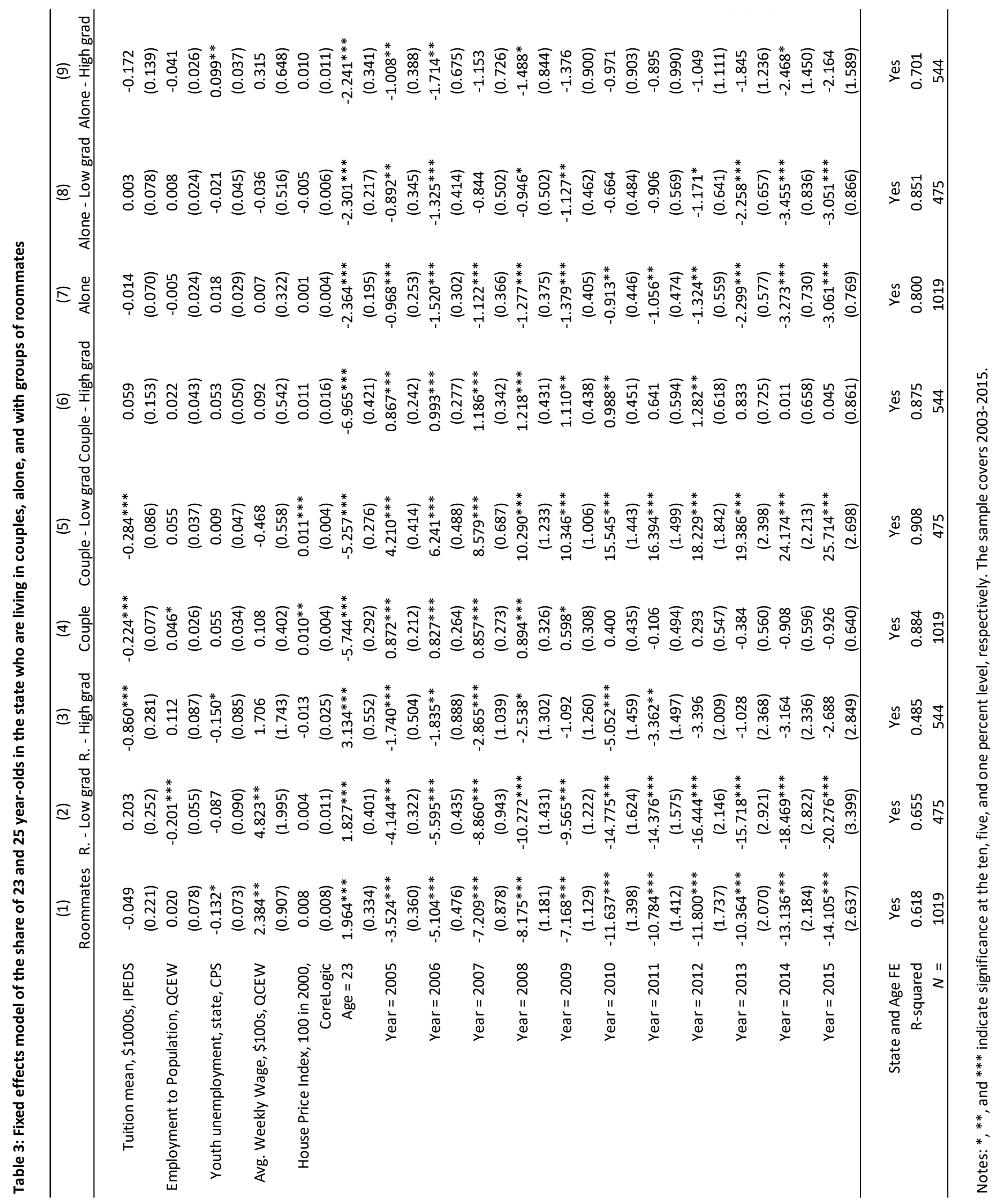


Table 4: Fixed effects model of the share of 23 and 25 year-olds in the state who are living with parents by region

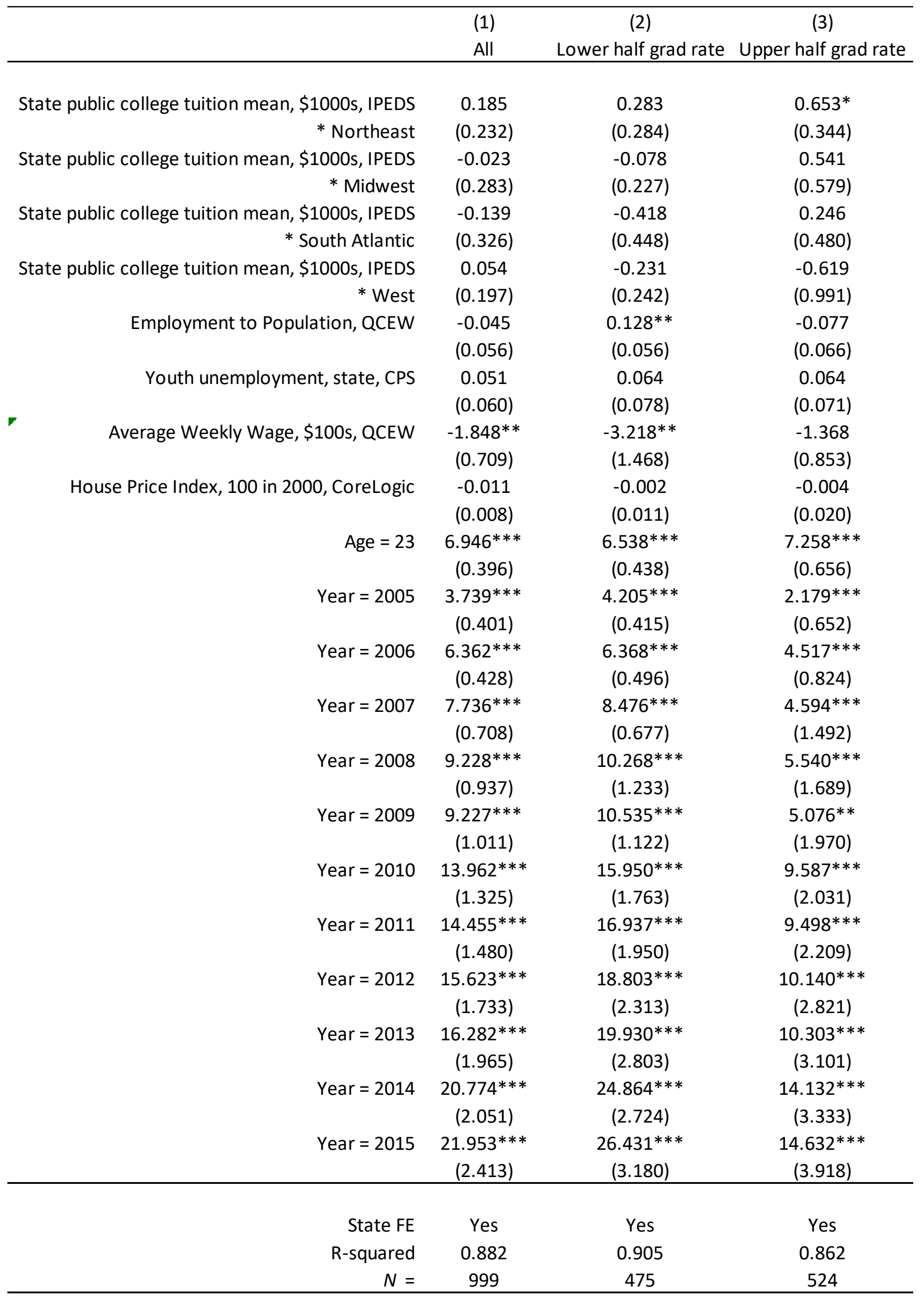

Notes: ${ }^{*}, * *$, and ${ }^{* * *}$ indicate significance at the ten, five, and one percent level, respectively. The sample covers 2003-2015. 
Table 5: Fixed effects model of the share of 23 and 25 year-olds in the state who are living with parents, urban v. rural

\begin{tabular}{|c|c|c|c|}
\hline & (1) & $(2)$ & (3) \\
\hline & All & Lower half grad rate & Upper half grad rate \\
\hline Percent of the state population living in & $-1.283 * * *$ & $-1.398 * * *$ & -0.082 \\
\hline urban areas & $(0.092)$ & $(0.120)$ & $(0.101)$ \\
\hline \multirow[t]{2}{*}{ State public college tuition mean, $\$ 1000$ s, IPEDS } & $-1.659 * * *$ & $-2.630 * * *$ & -0.302 \\
\hline & $(0.552)$ & $(0.816)$ & $(0.568)$ \\
\hline \multirow[t]{2}{*}{$\%$ living in urban areas * state mean tuition } & $0.020 * * *$ & $0.028 * * *$ & $0.011^{*}$ \\
\hline & $(0.005)$ & $(0.007)$ & $(0.006)$ \\
\hline \multirow[t]{2}{*}{ Employment to Population, QCEW } & -0.019 & $0.160 * * *$ & -0.067 \\
\hline & $(0.053)$ & $(0.045)$ & $(0.067)$ \\
\hline \multirow[t]{2}{*}{ Youth unemployment, state, CPS } & 0.042 & 0.032 & 0.049 \\
\hline & $(0.053)$ & $(0.073)$ & $(0.077)$ \\
\hline \multirow[t]{2}{*}{ Average Weekly Wage, \$100s, QCEW } & $-2.453^{* * *}$ & $-3.822 * *$ & $-1.535^{*}$ \\
\hline & $(0.806)$ & $(1.587)$ & $(0.835)$ \\
\hline \multirow[t]{2}{*}{ House Price Index, 100 in 2000, CoreLogic } & -0.003 & 0.003 & -0.011 \\
\hline & $(0.008)$ & $(0.010)$ & $(0.026)$ \\
\hline \multirow[t]{2}{*}{ Age $=23$} & $7.026 * * *$ & $6.498 * * *$ & $7.259 * * *$ \\
\hline & $(0.395)$ & $(0.429)$ & $(0.552)$ \\
\hline \multirow[t]{2}{*}{ Year $=2005$} & $3.720 * * *$ & $4.287^{* * *}$ & $2.181^{* * *}$ \\
\hline & $(0.392)$ & $(0.405)$ & $(0.537)$ \\
\hline \multirow[t]{2}{*}{ Year $=2006$} & $6.193 * * *$ & $6.245^{* * *}$ & $4.602 * * *$ \\
\hline & $(0.382)$ & $(0.488)$ & $(0.783)$ \\
\hline \multirow[t]{2}{*}{ Year $=2007$} & $7.699 * * *$ & $8.550 * * *$ & $4.797^{* * *}$ \\
\hline & $(0.626)$ & $(0.668)$ & $(1.040)$ \\
\hline \multirow[t]{2}{*}{ Year $=2008$} & $9.345^{* * *}$ & $10.363^{* * *}$ & $5.879 * * *$ \\
\hline & $(0.849)$ & $(1.205)$ & $(1.173)$ \\
\hline \multirow[t]{2}{*}{ Year $=2009$} & $9.463 * * *$ & $10.751 * * *$ & $5.420 * * *$ \\
\hline & $(0.901)$ & $(1.079)$ & $(1.211)$ \\
\hline \multirow[t]{2}{*}{ Year $=2010$} & $14.391 * * *$ & $16.375^{* * *}$ & $9.852^{* * *}$ \\
\hline & (1.198) & $(1.686)$ & $(1.348)$ \\
\hline \multirow[t]{2}{*}{ Year $=2011$} & $14.912^{* * *}$ & $17.430 * * *$ & $9.708 * * *$ \\
\hline & $(1.317)$ & (1.779) & $(1.425)$ \\
\hline \multirow[t]{2}{*}{ Year $=2012$} & $16.234 * * *$ & $19.351 * * *$ & $10.288^{* * *}$ \\
\hline & $(1.578)$ & $(2.163)$ & $(1.927)$ \\
\hline \multirow[t]{2}{*}{ Year $=2013$} & $17.109 * * *$ & $20.548 * * *$ & $10.450 * * *$ \\
\hline & (1.833) & $(2.722)$ & $(2.016)$ \\
\hline \multirow[t]{2}{*}{ Year $=2014$} & $21.486^{* * *}$ & $25.326 * * *$ & $14.250 * * *$ \\
\hline & $(1.851)$ & $(2.503)$ & $(2.041)$ \\
\hline \multirow[t]{2}{*}{ Year $=2015$} & $22.658^{* * *}$ & $26.744 * * *$ & $14.726 * * *$ \\
\hline & $(2.165)$ & $(2.914)$ & $(2.519)$ \\
\hline State and Age FE & Yes & & Yes \\
\hline R-squared & 0.884 & 0.906 & 0.864 \\
\hline$N=$ & 1019 & 475 & 544 \\
\hline
\end{tabular}

Notes: ${ }^{*}, * *$, and $* * *$ indicate significance at the ten, five, and one percent level, respectively. The sample covers 2003-2015. 
Table 6: County-level flow regression of parental co-residence, Moving in

\begin{tabular}{|c|c|c|c|c|c|c|}
\hline & $(1)$ & $(2)$ & (3) & (4) & $(5)$ & (6) \\
\hline Employment to Population, county, QCEW & $\begin{array}{c}-0.203^{* * *} \\
(0.050)\end{array}$ & $\begin{array}{c}-0.226 * * * \\
(0.052)\end{array}$ & $\begin{array}{c}-0.284 * * * \\
(0.039)\end{array}$ & $\begin{array}{c}-0.286 * * * \\
(0.040)\end{array}$ & $\begin{array}{c}-0.306 * * * \\
(0.041)\end{array}$ & $\begin{array}{c}-0.308 * * * \\
(0.041)\end{array}$ \\
\hline Average Weekly Wage, \$1000s, QCEW & $\begin{array}{c}-1.249 * * * \\
(0.360)\end{array}$ & $\begin{array}{c}-1.148 * * * \\
(0.364)\end{array}$ & $\begin{array}{c}-1.463 * * * \\
(0.372)\end{array}$ & $\begin{array}{c}-1.502 * * * \\
(0.382)\end{array}$ & $\begin{array}{c}-1.456 * * * \\
(0.357)\end{array}$ & $\begin{array}{c}-1.501 * * * \\
(0.365)\end{array}$ \\
\hline House Price Index, county, 100 in 2000, CoreLogi & $\begin{array}{c}0.043^{* * *} \\
(0.009)\end{array}$ & $\begin{array}{c}0.053^{* * *} \\
(0.009)\end{array}$ & $\begin{array}{c}0.068^{* * *} \\
(0.009)\end{array}$ & $\begin{array}{c}0.067 * * * \\
(0.009)\end{array}$ & $\begin{array}{l}-0.007 \\
(0.016)\end{array}$ & $\begin{array}{l}-0.008 \\
(0.016)\end{array}$ \\
\hline State public college tuition mean, $\$ 1000$ s, IPEDS & - & $\begin{array}{c}1.255^{* * *} \\
(0.207)\end{array}$ & - & $\begin{array}{l}-0.166 \\
(0.214)\end{array}$ & - & $\begin{array}{l}-0.194 \\
(0.214)\end{array}$ \\
\hline State \& Age FEs & Yes & Yes & Yes & Yes & Yes & Yes \\
\hline Linear trend & No & No & Yes & Yes & No & No \\
\hline Year FE & No & No & No & No & Yes & Yes \\
\hline R-squared & 0.028 & 0.034 & 0.036 & 0.036 & 0.042 & 0.042 \\
\hline$N=$ & 21,921 & 21,827 & 21,921 & 21,827 & 21,921 & 21,827 \\
\hline Mean of dependent variable & 17 & 17 & 17 & 17 & 17 & 17 \\
\hline
\end{tabular}

Notes: $* * *$, and $* * *$ indicate significance at the ten, five, and one percent level, respectively.

The sample covers 2003-2015. Observations other than tuition are measured at the county level. 
Table 7: County-level flow regression of parental co-residence, Moving out

\begin{tabular}{rcccccc}
\hline & $(1)$ & $(2)$ & $(3)$ & $(4)$ & $(5)$ & $(6)$ \\
Employment to Population, county, QCEW & & & & & & \\
& & & & & & \\
& $(0.101)$ & $(0.097)$ & $(0.097)$ & $(0.098)$ & $(0.102)$ & $(0.102)$ \\
Average Weekly Wage, county, \$1000s, QCEW & $-3.993^{* * *}$ & $-4.195^{* * *}$ & $-4.046^{* * *}$ & $-3.913^{* * *}$ & $-4.006^{* * *}$ & $-3.870^{* * *}$ \\
& $(0.662)$ & $(0.651)$ & $(0.652)$ & $(0.634)$ & $(0.671)$ & $(0.652)$ \\
& & & & & & \\
House Price Index, county, 100 in 2000, CoreLogic & 0.026 & 0.022 & $0.028^{*}$ & $0.028^{*}$ & -0.010 & -0.009 \\
& $(0.020)$ & $(0.016)$ & $(0.016)$ & $(0.016)$ & $(0.025)$ & $(0.025)$ \\
& & & & & & \\
State public college tuition mean, \$1000s, IPEDS & - & $-1.523 * * *$ & - & 0.537 & - & 0.535 \\
& & $(0.197)$ & & $(0.607)$ & & $(0.606)$ \\
& & & & & & \\
\hline State \& Age FEs & Yes & Yes & Yes & Yes & Yes & Yes \\
Linear trend & No & No & Yes & Yes & No & No \\
Year FE & No & No & No & No & Yes & Yes \\
R-squared & 0.020 & 0.030 & 0.035 & 0.036 & 0.037 & 0.038 \\
$N=$ & 18,873 & 18,806 & 18,873 & 18,806 & 18,873 & 18,806 \\
Mean of dependent variable & 38 & 38 & 38 & 38 & 38 & 38 \\
\hline
\end{tabular}

Notes: $*, * *$, and $* * *$ indicate significance at the ten, five, and one percent level, respectively.

The sample covers 2003-2015. Observations other than tuition are measured at the county level. 